\title{
Radiopharmaceutical enhancement by drug delivery systems: A review
}

\author{
Janke Kleynhans $^{\mathrm{a}, \mathrm{b}}$, , Anne Frederica Grobler ${ }^{\mathrm{a}, \mathrm{b}}$, Thomas Ebenhan ${ }^{\mathrm{b}, \mathrm{c}}$, Mike Sathekge ${ }^{\mathrm{b}, \mathrm{c}}$, Jan Rijn Zeevaart ${ }^{\mathrm{a}, \mathrm{b}, \mathrm{d}}$ \\ a Department of Science and Technology, Preclinical Drug Development Platform, North-West University, Potchefstroom 2520, South Africa \\ b Preclinical Imaging Facility, NuMeRi, Pelindaba, Brits 0242, South Africa \\ c Nuclear Medicine, University of Pretoria and Steve Biko Academic Hospital, Pretoria 0001, South Africa \\ d Radiochemistry, The South African Nuclear Energy Corporation (Necsa), Brits 0240, South Africa \\ ${ }^{*}$ Corresponding author.Email address: jankekleynhans@gmail.com (J. Kleynhans)
}

\begin{abstract}
A B S T R A C T
Introduction: Drug delivery systems are entities designed to alter the biological behaviour of the pharmaceutical active ingredients that they carry in order to afford more beneficial biodistribution and safety profiles. Many problems currently faced by the field of nuclear medicine (e.g. developing new theranostic agents, utilizing mul-timodal imaging platforms and providing targeted delivery) can be facilitated by applying drug delivery systems to radiopharmaceuticals that have been proven successful in other medical fields. This review describes the advancements being made towards this goal.

Areas covered: All aspects of drug delivery systems (liposomes, nanoparticles, microspheres) in the field of nuclear medicine are discussed. Only systems with foreseen or confirmed clinical applications in nuclear medicine are discussed, not instances where nuclear imaging is merely a tool to evaluate the biodistribution of novel delivery technologies.

Conclusion: Great advancements have been made with the development of novel systems incorporating nuclear entities in drug delivery systems, with the possibility of reshaping the nuclear medicine landscape. Nonetheless, translation from preclinical evaluations to clinical use is lacking and serious investment needs to be made towards this goal.
\end{abstract}

Keywords:

Nuclear medicine Drug

carrier systems

Radiopharmaceuticals

Theranostics

Multi-modality imaging

\section{Introduction}

Drug delivery systems can provide solutions to the continuously growing social and economic problems faced by modern health care [1-3]. Currently there is great concern regarding a decrease in the number of new pharmacological agents registered with the FDA (Food and Drug Administration, USA) which may be a symptom of a reduction in the number of drugs entering the different phases of the drug development pipeline. A substantial number of tested entities' development is abandoned due to toxicity, low activity at the target site, unsuitable pharmacokinetic profiles and the lack of absorption across biological membranes [4-7]. Drug delivery systems (see Table 1) pro- motes the concentration of the drug reaching the target site and the enhancement of less than favourable pharmacokinetic profiles. This allows the revisiting of failed compounds with the opportunity to adjust the relationship between safety and efficacy as well as the possibility to administer a lower dosage reducing the risk of adverse effects $[1,8,9]$.

This issue is by no means limited to therapeutic agents alone and the same plague is hampering radiopharmaceutical production [14]. Due to the escalating shortage of medical isotopes, in particular molybdenum-99 ( $\left.{ }^{99} \mathrm{Mo}\right)$ and subsequently technetium-99m $\left({ }^{99 m} \mathrm{Tc}\right)$, the more effective delivery of radiopharmaceuticals will ensure a lowering in the demand for these agents. Whilst enormous amounts of capital are invested in the development of more sensitive detecting equipment to allow for a decrease of isotope dosage administered per patient scan (re-

Abbreviations: ALARA, As Low As Reasonably Achievable; BMEDA, $N, N$-bis [2-mercaptoethyl]- $N^{\prime}, N^{\prime}$-diethylethylenediamine; CLI, Cerenkov Luminescence Imaging; CT, Computed

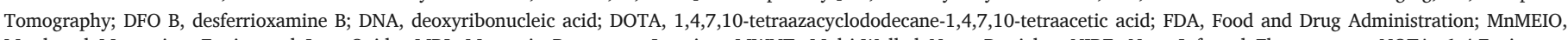

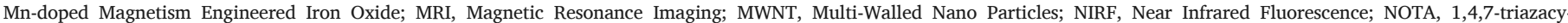

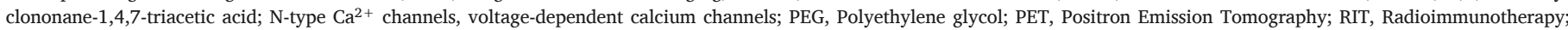

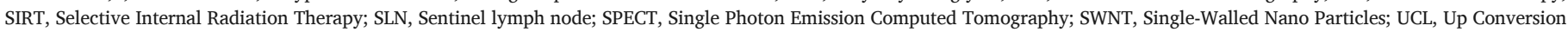
Luminescence. 
Table 1

Characteristics of drug carrier systems [10-13].

\begin{tabular}{|c|c|c|c|}
\hline & Liposomes & Microspheres & Nanoparticles \\
\hline Components & $\begin{array}{l}\text { Phospholipid } \\
\text { vesicles with } \\
\text { one or more } \\
\text { lipid bilayers } \\
\text { encompassing } \\
\text { an aqueous } \\
\text { phase. }\end{array}$ & $\begin{array}{l}\text { Manufactured } \\
\text { from various } \\
\text { material, most } \\
\text { commonly } \\
\text { glass, } \\
\text { polymers and } \\
\text { ceramic. }\end{array}$ & $\begin{array}{l}\text { Unlimited } \\
\text { materials may be } \\
\text { used as long as } \\
\text { the material } \\
\text { exhibits novel } \\
\text { properties due to } \\
\text { the reduction in } \\
\text { size. }\end{array}$ \\
\hline Size & $\begin{array}{l}\text { Small }(\leq 100 \\
\text { nm) } \\
\text { Intermediate } \\
(100-250 \\
\mathrm{nm}) \\
\text { Large ( } \geq 250 \\
\mathrm{~nm}) \\
\text { Giant }(>1 \\
\mu \mathrm{m})\end{array}$ & $1-1000 \mu \mathrm{m}$ & $1-100 \mathrm{~nm}$ \\
\hline Pros & $\begin{array}{l}\text { Very } \\
\text { adaptable } \\
\text { system }\end{array}$ & $\begin{array}{l}\text { Easy } \\
\text { manufacturing } \\
\text { Biocompatible } \\
\text { Slow-release } \\
\text { capability }\end{array}$ & $\begin{array}{l}\text { Adaptable and } \\
\text { easily } \\
\text { functionalized } \\
\text { with targeting } \\
\text { entities }\end{array}$ \\
\hline Cons & $\begin{array}{l}\text { Mostly } \\
\text { unstable } \\
\text { Repeatability } \\
\text { of production } \\
\text { and quality } \\
\text { control } \\
\text { difficult }\end{array}$ & $\begin{array}{l}\text { Drug release } \\
\text { from particle } \\
\text { not always } \\
\text { controlled }\end{array}$ & $\begin{array}{l}\text { Questions remain } \\
\text { regarding the } \\
\text { safety of these } \\
\text { systems }\end{array}$ \\
\hline
\end{tabular}

ducing risk of exposure as well as cost), drug delivery systems may provide a similar dosage reduction without the need of any investment on additional hardware by medical facilities $[15,16,17]$. Selective targeting to the regions of interest is also important for radiopharmaceuticals since failure to accumulate at the target site, will reduce image quality and result in the presence of artefacts. Since the ALARA (As Low As Reasonably Achievable) principle will always be an important goal in the medical application of nuclear isotopes, the reduction of the dosage administered will contribute further to the safety of medical personnel and patients.

With the development of new theranostic (radiopharmaceutical agents with application in both diagnosis and treatment) radiotracers, the targeting becomes a great priority due to high amounts of irradiation during the treatment phase (associated with repeated dosing) and possible side-effects in unspecific delivery areas. In the context of radiopharmaceuticals, a theranostic agent will combine a PET (Positron Emission Tomography) or SPECT (Single Photon Emission Computed Tomography) isotope to act as a biomarker for imaging of the target but simultaneously incorporate a therapeutic entity (for example immunotherapeutic drugs or chemotherapeutic drugs) that will be delivered at the same area of biodistribution. Although radiopharmaceutical theranostics are mainly focused on the treatment of cancer, other applications are currently under investigation such as agents developed to combat infectious diseases [18-20].

Nowadays diagnosis is mostly based on the information received from more than one modality to increase the accuracy of information. The concurrent measurement of both anatomic and physiological data solves the issues regarding accurate localization of nuclear signals [21-26]. The combination of PET/CT and SPECT/CT has become standard practice and individual scanners are rarely employed [27]. Due to the successes of the tandem technologies, various other combinations of modalities are under development (for example PET and magnetic resonance imaging-[MRI]), sometimes necessitating the combination of more than one tracer, for instance a radiopharmaceutical as well as a contrast agent [28-32]. To ensure that all the administered tracers be- have in the same pharmacokinetic pattern and that the results are interconnected, these individual entities can be packaged in one drug delivery system. During the hybridization of two imaging techniques it is important that the system will, above all, provide added clinical benefit that cannot be obtained with other interventions [33].

Almost every group of drug delivery systems developed, has been applied in the radiopharmaceutical field $[34,35]$. Probably contributing to these investigations is the fact that these systems are routinely labelled with an isotope to follow their movement in living organisms without disturbing the natural functioning of the system in question [36-38]. Often it is then brought to light that the properties of the isotope employed to evaluate the drug carrier system, deviates from its normal behaviour when entrapped in the entity. If these new qualities can contribute novel possibilities to the arsenal of diagnostic entities available to the medical world, a logical next step is to launch further investigation $[37,39]$. Only drug delivery systems paired with radiopharmaceuticals that demonstrated foreseen diagnostic value are included in this review. Radiopharmaceuticals utilized purely for the sake of evaluation of the biological functioning of the drug delivery system are excluded from this assessment. It is important to note that in a sense, radiopharmaceutical tracers can already be viewed as a carrier system that locates the selected isotope at a specific target site due to ligand interactions. This review will focus exclusively on known drug carrier systems traditionally applied in pharmaceutical delivery (for example liposomes and nanoparticles), with applications in the field of nuclear medicine.

\section{Liposomes}

Liposomes are drug carrier systems that incorporate bilayers of lipids encapsulating a hydrophilic interior where the active pharmaceutical ingredient accumulates. Other variations of this technology (for example oil-emulsions type systems) occur with different interplays between hydrophobic and hydrophilic layers. Liposomes are extremely versatile (Fig. 1) and can be tailor-made to suit the entity to be delivered as well as the characteristics of the cellular target to be reached. The consensus is that the hydrophilic pharmaceutical active ingredient will become entrapped in the system whilst the lipid component thereof, will allow for the transportation through hydrophobic biological barriers to release the load at the area of interest. Liposomes as drug delivery systems have produced substantial results with various products reaching the marketing phase. There is however a large discrepancy between the amount of preclinical work and products researching the market [40-44].

Liposomes can be adapted in various manners (see Fig. 1) to enhance the efficacy of their payload delivery. A very important characteristic of liposomes is the accumulation by enhanced permeation and retention (EPR). The blood vessels of tumours have abnormally large endothelial tight junction gaps which allows for the penetration of drug carriers and accumulation. The intact barriers of normal blood vessels does not allow for the movement of these larger molecules to tissue and this leads to higher accumulation in tumours [45]. The modification of the surface of the liposome (i.e. incorporating monoclonal antibodies for immunoradiotherapy or targeting ligands) can ensure the distribution of the liposome to the target tissue through active targeting. Another way of targeting the release of the active ingredient is with $\mathrm{pH}$ sensitive liposomes. Liposomes sensitive to $\mathrm{pH}$ is destabilised in an acidic environment (e.g. tumour tissue) where upon the contents is released [46]. When the liposome surface is modified to contain polyethylene glycol (pegylated) this results in the longer circulation of liposomes due to higher membrane integrity. If a longer circulation is combined with the EPR effect, this allow for an increased time frame for accumulation at tumour tissue [47]. The lipids incorporated in the liposome can also be adapted with chelators to allow for the direct la- 


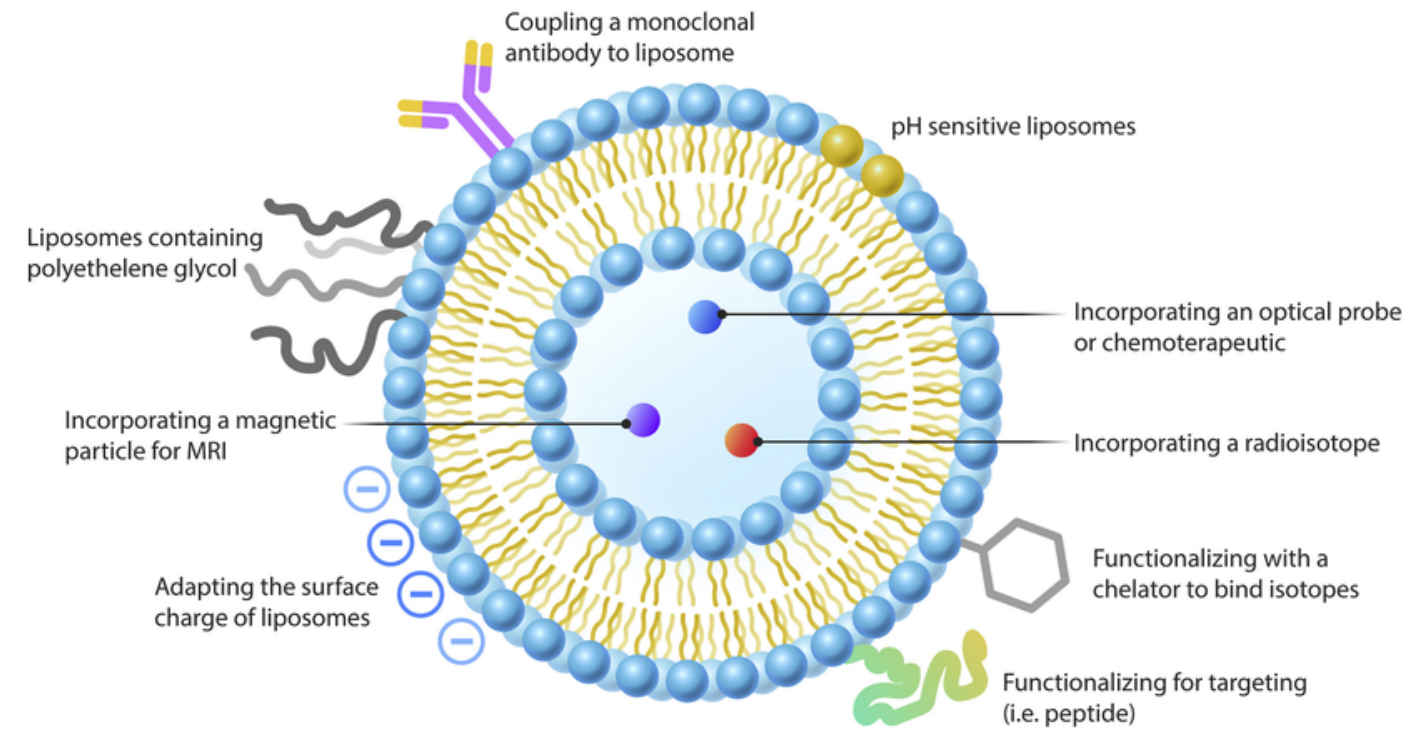

Fig. 1. A liposome with the different adaptations as included in this review.

belling of these drug carriers. Various isotopes and radiotracers have been incorporated in liposomes, either alone or with other tracers (MRI or optical) or therapeutic agents.

When the EPR effect is used, it is important to strike a balance between size, with a larger system allowing for the selective leakage to the tumour tissue as well as extending the residence in the circulation. But if the drug carrier is to large (leading to the failure carrier systems fail) this could oppositely lead to a failure of crossing all the biological barriers in order to penetrate to the direct target of action. A feasible strategy is to combine both active targeting (with targeting ligand) with passive targeting (due to size) and ensure that all the barriers for absorption (including removal through the reticuloendothelial system) is negated. Overall the lack in clinical translation of drug carrier systems must be a warning to researchers in this field, that the successful development of such a system requires intensive investigations and a very complex dynamic that needs to be addressed as a whole.

The labelling of liposomes can be done by various strategies. Goins and co-workers investigated various methods of manufacturing liposomes which allows for the "afterloading" of liposomes. This is the process of adding the radiopharmaceutical after the liposome is manufactured and not during the process of liposome assembly. This process is more beneficial if the half-life of most radiopharmaceuticals is considered. The liposome is manufactured with an interior component that promotes the movement of the tracer across the lypohillic membrane. One method is to encapsulate glutathione in the liposome which forms an interaction with the radiotracer once it crosses the lipid bilayer and keeps it entrapped. Transport across the bilayer is enhanced by complexing the isotope with a lypohillic chelator - in this case $\mathrm{N}, \mathrm{N}$-bis(2-mercaptoethyl)-N',N'-diethylethylenediamine (BMEDA) or hexamethylpropyleneamine oxime (HMPAO). Another strategy includes the generation of a $\mathrm{pH}$ gradient with ammonium sulphate across the liposome interior ( $\mathrm{pH} \mathrm{5.1)} \mathrm{and} \mathrm{the} \mathrm{liposome} \mathrm{exterior}(\mathrm{pH}$ 7.4) [48]. Liposomes for nuclear medicine applications are mostly synthesised in a similar way [49-56]. Other methods includes adsorption or entrapment of the radiochemical to the liposome (with or without funtionalization of lipid component) with prolonged incubation [57-61] as well as the use of an ionophore (for example 2-hydroxyquinoline) to transport the radiochemical across the membrane [62]. With radioisotopes that have a longer half-life (like iodine-124), it is possible to include the radioactive isotope in the synthesis of the liposome, or complex it with the individual components before assembly [63].

\subsection{Rhenium containing liposomes as theranostics}

Since liposomes for other non-nuclear applications have been extensively characterized it is no surprise that the Institute of Nuclear Energy Research (Taiwan) has already advanced a lipid theranostic agent into Phase 1 clinical testing (ClinicalTrials.gov identifier NCT02271516), although the trial is currently not yet in the recruiting stage. The tested liposome system contains rhenium-188 as a dual imaging (155 $\mathrm{keV}$ gamma emission) and therapeutic isotope $(2.12 \mathrm{MeV}$ beta emission) linked to BMEDA ( $N, N$-bis [2-mercaptoethyl]- $N^{\prime}, N^{\prime}$-diethylethylenediamine) acting as chelator. The chelator-isotope complex is entrapped into the fully assembled pegylated liposomes by a remote loading method before administration [48]. Preclinical studies demonstrated the ability of the liposomes to passively target rhenium-188 with EPR to various neoplasms in the gastrointestinal tract. The survival rate was increased in a C26 colon carcinoma ascites mice model, with inhibition of both the tumour and subsequent ascites $[49,50]$. Compared to the gold standard treatment of 5-fluorouracil for colon carcinoma as well as colonic peritoneal carcinomatasis, $\left[{ }^{188} \mathrm{Re}\right] \mathrm{Re}$-BMEDA liposomes exhibited a higher therapeutic efficacy in rodent xenografts [50, 64]. No severe toxicity was demonstrated in the selected rodent models. High dosages were associated with short term weight-loss, a temporary reduction in haematological parameters and a cytogenetic risk [65, 66]. Synergistic enhancement of the efficacy of this system is reported with concomitant administration of doxorubicin liposomes as well as external beam radiotherapy $[67,68]$. The short physical half-life of this isotope as well as the availability of a tungsten-188/rhenium-188 generator bodes well for its theranostic application.

Other pre-clinical applications of rhenium isotopes entrapped in liposomes showing promise in vivo include pancreatic cancer, glioma, head and neck cancer, lung metastases, breast cancer and intraperitoneal treatment of ovarian cancer [69-76]. Rhenium-188 has also been incorporated in various other drug carrier systems - none yet transitioned into clinical testing [77-80].

\subsection{Multimodal imaging liposomes}

An example of multimodal imaging liposomes contains the paramagnetic radiopharmaceutical zirconium-89 labelled octreotide as well as gadolinium. This liposome showed good targeting for the somatostatin receptor subtype 2 , with both probes incorporated in the lipid 
phase during the manufacturing of the liposome. This combination can provide high-resolution anatomical information through MRI as well as functional information offered by the PET component [57]. Various copper-64 labelled liposomes are also under investigation for possible clinical use. These can be manufactured by covering the superparmagnetic iron core for MRI contrast with phospholipids which allows for chelating with copper-64 as PET imaging agents [81]. Liposomes also have the ability to entrap radiotracers and fluorophores without having an effect on in vivo distribution characteristics of the drug carrier, allowing for adaptability of this system for various targets as needed.

A liposome carrying hexadecyl-4-[ $\left[{ }^{124} \mathrm{I}\right]$ iodobenzoate as well as a gadolinium-1,2-dipalmitoyl-sn-glycero-3-phosphoetahnolamine-complex is also under development. The choice of radioisotope is based on the long half-life of iodine-124 (4.2 days) which allows ample time for production (radiolabelling before assembly) and follow-up scan procedures post-administration. Iodine-124 also emits strong Cerenkov luminescence that allows for optical imaging. MRI is provided by the inclusion of a gadolinium complex. The components of this liposome were adapted to enable the fast removal of carriers from the reticuloendothelial system and prolonged retention at the tumour site resulting in clear images with minimal background interference [63].

\subsection{Multimodal theranostics}

Li et al. designed a liposome to carry gadolinium (MRI), a near infrared fluorescence (NIRF) dye (IRDye-DPSE) and either technetium-99m (SPECT) or copper-64 (PET) for multimodal imaging. Following through with a theranostic approach, doxorubicin could be post-loaded onto this system to target tumour cells. It is clear that the liposome carrier system offers unique capabilities to entrap as many different probes and therapeutic entities into one core, as is desired [51]. Zielhuis et al. successfully synthesized liposomes loaded with holmium-166 to provide beta- and gamma emission as a therapeutic component, technetium-99m for SPECT and paramagnetic gadolinium for MRI. In vivo studies are yet to be undertaken [58].

\subsection{Radiochemotherapeutics}

The indium-111 labelled vinca alkaloid vinorelbine, which inhibits cell growth, was proposed as a colon carcinoma theranostic agent when formulated in a liposome. Promising results were obtained in three studies on xenograft rodents, with passive targeting of tumour cells allowed by the pegylated nanoliposomes entrapping the combination. The system showed an increased reduction in tumour growth and less toxicity with this system compared to unformulated vinorelbine [59, 82, 83]. Since rhenium isotopes (rhenium-186 and rhenium-188) have intrinsic theranostic capabilities due the release of energy that is capable of both being cytotoxic and being useful for imaging, the combination with a chemotherapeutic agent like doxorubicin can have substantial benefits. This system was evaluated for the treatment of head and neck cancer in rat xenografts and displayed a reduction in tumour size with a good toxicity profile [52]. Another agent for colorectal cancer, sorafenib, was combined with rhenium-188 in a liposome carrier and this compound also demonstrated viability in a mouse cancer model [84].

The concept of theranostic radiochemotherapeutics is not limited to cancer therapy and also demonstrates possibilities in anti-infective therapy. Liposomal radiochemotherapeutics for mycobacterial infections were developed utilizing ofloxacin and rifampicin combined with technetium-99m for SPECT imaging. In this instance the application might not truly be purely theranostic, but also that of a companion diagnostic depending on the outcome of the clinical trials. Preliminary studies on this system show in vitro efficacy against mycobacteria as well as in vivo targeting efficacy confirmed by SPECT imaging in an in- fected mouse model [60]. A companion diagnostic is a diagnostic agent used as pre-treatment to determine the applicability of the therapeutic drug as treatment. These agents are developed based on the biomarkers that predict the efficacy of toxicity of the planned treatment [85]. When a theranostic agent is developed which entraps two different entities in one drug carrier system, it is important that the dosing characteristics of these agents (e.g. dosage frequency required) are marriageable to avoid overexposure to a particular entity. In the case of the packaging of radioisotopes in a system with other pharmaceuticals, this becomes even more important due to ALARA principles and the safety of the patient.

\subsection{Liposomes in alpha therapy}

Alpha-particle emitters are potent cytotoxic agents (due to high linear energy transfer) with a DNA damage capacity far greater compared to beta emitters. With their high linear energy transfer (LET) and short penetration ranges $(\sim 30 \mu \mathrm{m})$, just a few alpha tracks through the nucleus of a cell are sufficient to cause apoptosis (due to double strand breaks in cellular DNA). The damage to healthy cells can be limited if the alpha emitter is successfully targeted to tumour tissue due to the small radiation distance exhibited by these agents. Actinium-225 is a very promising radionuclide for targeted alpha therapy (TAT). With its relatively long half-life (9.9 d) it has enough time to target also less-easily accessible tumours, and the 4 emitted alpha's in the decay chain ensure optimal damage once at the targeted site. However, upon the emission of an alpha particle, the daughter nuclide experiences a recoil energy. This recoil energy is several orders of magnitude larger than the energy of the chemical bond of the nuclide with a targeting antibody or peptide. The daughter nuclide will thus break free after the first decay, and in the case of actinium-225 this is particularly problematic as the first daughter is fransium-221. Francium is a potassium analogue and as is excreted from the cell by the $\mathrm{Na} / \mathrm{K}$ pump with subsequent decay (generation of the rest of the 3 alpha emissions) happening outside the target. This will lead to off-target radiation which diminishes the potential as a therapeutic radionuclide. Although recent clinical studies with actinium-225 alpha-particle emitting agents have given remarkable results, routine clinical implementation is overshadowed by the above as well as the limitation of the shortage of the radionuclide supply [86, 87].

One of the approaches to overcome this is encapsulation in drug carriers, where (partial) retention of the daughter nuclides can be achieved. Polymersomes (seen as an synthetic analogue of liposomes) have shown to be very efficient in encapsulating actinium-225 and retaining its recoiling daughters. These carriers can be passively targeted to tumour tissue through the EPR effect with further targeting improvement brought about by attaching targeting moieties. Recently very encouraging results were obtained with actinium-225 loaded polymersomes and liposomes in in vitro experiments. No animal evaluations or human trials are published in literature at this stage [61, 86-93].

\subsection{Liposomes for targeted imaging}

A liposomal SPECT imaging agent, Vescan ${ }^{\circledR}$ (containing ${ }^{111}$ Indium) was developed in the 1980 s for the imaging of tumours. This agent was proven effective in various clinical trials including a Phase II and Phase III trial but was never commercialized [53, 86-90]. Long circulating pegylated liposomes containing ${ }^{111}$ In was also investigated clinically in human trials with positive results indicating accumulation at tumour sites and reduced scavenging by the reticuloendothelial system [86, 87].

In order to change the pharmacokinetic properties of [ $\left.{ }^{99 \mathrm{~m}} \mathrm{Tc}\right] \mathrm{Tc}-\mathrm{MIBI}$ ([$\left.{ }^{99 \mathrm{~m}} \mathrm{Tc}\right] \mathrm{Tc}-$ hexakis-2-methoxyisobutylisonitrile) to allow for tumour imaging, Belhaj-Thayeb et al. entrapped it in pegylated lipo- 
somes. In vivo biodistribution studies show evidence of a higher accumulation in tumours as well as longer retention in blood circulation to make it a feasible option for the imaging of cancer lesions [54]. The linking of liposomes with pure pertechnetate was also investigated in animal models and avoidance of the reticuloendothelial system was accomplished with the adaptation of the surface charge of particles [55]. Incorporating ${ }^{99 \mathrm{~m}} \mathrm{Tc}$ in a nanosystem comprising of folated- $\gamma$-glutamic acid and chitosan had positive effects on intratumoral applications in an in vivo study [91]. Liposomes coupled with vasoactive intestinal peptide also showed a higher accumulation of their entrapped [ $\left.{ }^{99 \mathrm{~m}} \mathrm{Tc}\right] \mathrm{Tc}-\mathrm{HM}-$ PAO ([ $\left.{ }^{99 \mathrm{~m}} \mathrm{Tc}\right] \mathrm{Tc}$-hexamethylpropyleneamineoxime) in breast cancer xenografts [92]. To predict the efficacy of therapy by liposomes containing chemotherapeutic drugs (for example Doxil®), Kleiter et al. [93] evaluated the effects of co-administered $\left[{ }^{99 \mathrm{~m}} \mathrm{Tc}\right] \mathrm{Tc}$-liposomes. It was verified that both types of liposomes accumulated similarly without having any effect on the distribution of one another and this is therefore a valid method for prediction of therapy outcomes. The pre-administration of a labelled liposome might therefore afford the same qualities as theranostic agents in the case of Doxil ${ }^{\circledR}$ therapy success prediction and the provision of possible side-effect expectations. Different liposomes containing galium-67 was developed with surface charge variations and it was shown that these systems can differentiate between tumours and inflammation during in vivo evaluations. Various adaptations enhanced tumour delivery but these liposomes never translated to clinical use [94-96]. Liposomes have been developed to target copper-64 to neuroendocrine tumours, breast cancer lesions and head and neck cancer, with all of these systems demonstrating promising enhancement of accumulation in tumour tissue in vivo [62, 97-99].

In some instances, the use of liposomes for imaging has been negatively influenced by the EPR effect, resulting in a high background noise during imaging. A method was developed to remove liposomes from circulation once tumour accumulation is sufficient. This system is based on the strong affinity of biotin to bind to avidin. The radiotracer containing liposomes were functionalized with biotin and upon administration of avidin $2 \mathrm{~h}$ later, all residual liposomes were collected and removed from the circulation by the reticuloendothelial system providing a neat solution to reduce background interference $[100,101]$.

\subsection{Liposomes for radioimmunotherapy}

Radioimmunotherapy (RIT) involves the isotope providing therapeutic radiation being coupled to a mAb with affinity to tumour tissue directly targeting the malignancy. The concept is mainly focused on the passive targeting ability of liposomes to accumulate more RIT molecules at the tumour site. Jestin and co-workers $[102,103]$ manufactured various liposome nanocapsules containing haptens and technetium-99m complexes with affinities for bispecific anti-bodies in tumour tissue.

\subsection{Imaging infection and inflammation}

The differentiation between infection and sterile inflammation is always a conundrum in the clinical setting. Distinguishing between these two disease processes allows for administration of the most appropriate therapy for the particular manifestation [104]. A first in-human study determined that technetium-99m labelled liposomes with a negatively charged surface demonstrate a tendency to localize at inflammation caused by rheumatoid arthritis. No side-effects were experienced by the test subjects. This system uses the normally unwanted effect of the reticuloendothelial system to accumulate liposomes due to a higher presence of these cells in the inflamed synovial tissue. It is important to note that this system does not distinguish between infection and sterile inflammation [105-107]. Dams et al. also verified the efficacy of pegy- lated liposomes labelled with technetium-99m to visualize infection and inflammation establishing this system as an effective imaging agent in human trails. However, again no distinction between infection and inflammation exists [56]. A first-in-human trial evaluating the efficacy of [99m Tc]Tc-PEG-liposomes for imaging inflammation due to Chron's disease showed good efficacy but also substantial side-effects (dyspnoea and facial erythema) which caused the termination of the investigation [108]. Modification of the system is needed before further application can take place. Various animal studies are published on the visualization of infection or inflammation in animal models by technetium- $99 \mathrm{~m}$ or indium-111 containing liposomes without determining the ability of selectivity for infection imaging above inflammation [109-116].

In an effort to develop nuclear imaging agents that distinguish between bone infection as opposed to aseptic bone inflammation, Ferreira and co-workers coupled ceftizoxime to long-circulating $\mathrm{pH}$-sensitive liposomes (labelled with technetium-99m). This liposome harnesses the broad-spectrum antibiotic properties of this antibiotic to target bacterial cell walls and accumulate by preference at areas of infection. Selectivity for infection was ascertained in vivo (Fig. 2) and was subsequently further enhanced by performing two imaging procedures, 8 hours apart [117]. It is important that targeting strategies such as these, which focus on disease specific mechanisms, are further developed in order to provide agents that effectively distinguish between infection and inflammation.

\subsection{Blood pool imaging}

Liposomes coupled with technetium-99m have been developed as blood-pool imaging agents that provide a system independent from the injection of radiolabeled red blood cells. These liposomes did show good stability and prolonged blood circulation time and pegylated liposomes ensured that liver accumulation is reduced $[118,119]$.

\subsection{Neurological imaging}

Although $\left[{ }^{18} \mathrm{~F}\right]$ deoxyfluoroglucose is currently used as the standard imaging agent for visualization of brain tumours, controversy surrounds its usefulness since brain tissue (similarly to tumours) exhibits a high glucose consumption. A search for new agents that might proof more accurate and useful is therefore on-going. Liposomes that contains 1-[ $\left.{ }^{18} \mathrm{~F}\right]$ fluoro-3,6-dioxatetracosane exhibits a higher contrast in vivo during the imaging of brain glioma compared to that of the gold standard $\left[{ }^{18} \mathrm{~F}\right]$ deoxyfluoroglucose. The liposomes did not distribute to normal brain tissue due to an inability to cross the blood-brain barrier, but even the smallest tumour lesion was picked up with this liposomal tracer [120].

A novel application of liposomal flourine-18 would be the imaging of synaptic density in the brain by targeting voltage-dependent calcium channels (N-type $\mathrm{Ca}^{2+}$ ). This tracer can image neurodegeneration and evaluate cognitive function during therapy. A derivative of $\omega$-conotoxin is bound to flourine-18 to form $\mathrm{K} 24-\left[{ }^{18} \mathrm{~F}\right]$-GVIA, a tracer that has affinity for $\mathrm{Ca}^{2+}$ channels with the affinity to be entrapped in liposomes. The liposomes were modified to enhance brain penetration by incorporation of cerebroside 3-sulfate - a constituent of myelin sheath tissue. The viability of this research needs to be proven in vivo and clinically, but this is a good example of the versatility of liposomes to be adapted for targeting different regions of interest [121].

It is possible to label whole blood with $\left[{ }^{15} \mathrm{O}\right]$-oxygen to measure the oxygen consumption in humans, but this has the propensity to damage red blood cell function and necessitate removal of the protein fraction by the washing of red blood cells. Tiwari and colleagues are proposing the use of liposomes containing haemoglobin labelled with $\left[{ }^{15} \mathrm{O}\right]$-oxygen to be injected as a type of surrogate red-blood cell for the measure- 
$1 \mathrm{~h}$

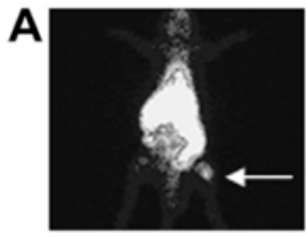

B
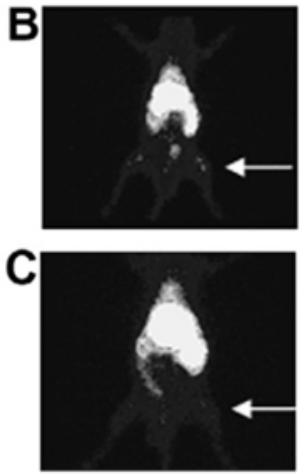

$2 \mathrm{~h}$
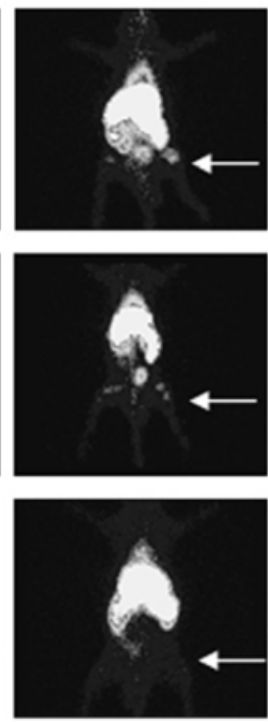

$4 \mathrm{~h}$
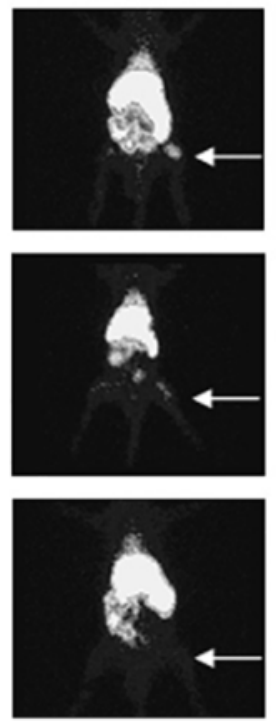

$6 \mathrm{~h}$
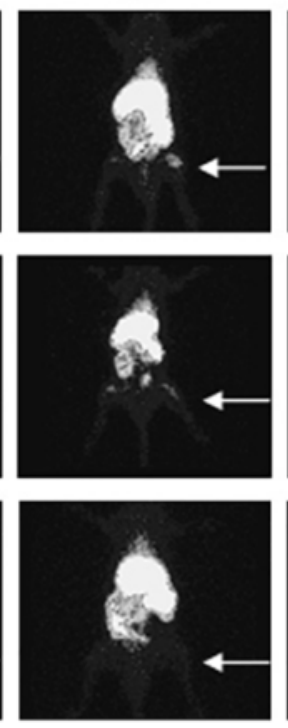

$8 \mathrm{~h}$
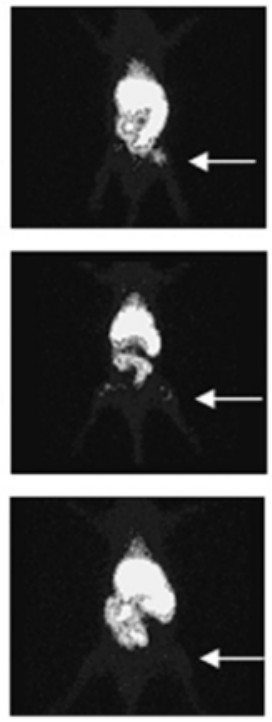

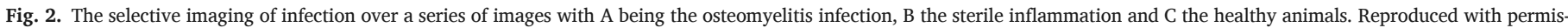
sion from the reference [117].

ment of brain oxygen consumption [122]. This method provides a tracer that effectively measures the cerebral metabolic rate of oxygen consumption in rats and may have further applications in the clinical setting. It is however important to note that the half-life of oxygen-15 is extremely short (2.04 minutes) and restrictions therefore exist regarding clinical usage [123].

\subsection{Protection against degradation}

Certain peptides are unstable when circulating in body fluids. For instance the use of bombesin, which binds to gastrin-releasing peptide receptors that are over expressed in certain tumours, is hampered by the susceptibility of this peptide to destruction by biological fluids. In order to utilize $\left[{ }^{99 \mathrm{~m}} \mathrm{Tc}\right] \mathrm{Tc}$-bombesin as a radiotracer, De Barros et al. formulated long circulating liposomes containing this tracer and demonstrated the viability to image breast cancer tumours in vivo [124]. Drug carrier systems can therefore provide additional protection of sensitive proteins and enable their use as tracers for nuclear imaging.

\section{Microspheres}

Included in this review are microsphere technologies which, although not in the nanoscale range, are still effective delivery systems that change the behaviour of the materials they carry. These entities are small spherical structures with dimensions between $10 \mathrm{~nm}$ to $1000 \mu \mathrm{m}$ made of a wide range of materials that integrates the active ingredient in a stable solid form of uniform size $[125,126]$.

\subsection{Microspheres as therapeutic agents}

One such instance is microspheres (bioactive glass) combining samarium-153 with doxorubicin for the treatment and palliation of bone cancer. These microspheres are however still in the development phase and have not been evaluated preclinically [127].

For application of selective internal radiation therapy (SIRT) in hepatocellular carcinoma, two types of microspheres are currently used in the clinical setting namely the TheraSphere ${ }^{\circledR}$ and SIR-Sphere ${ }^{\circledR}$. The TheraSphere ${ }^{\circledR}$ was developed as an insoluble, damage and irradiation resistant carrier of yttrium-90, developed due to previously investigated resin-bead microspheres resulting in fatal adverse events. These were caused by the leaching of yttrium-90 out of the system and subsequent distribution to the bone marrow [128]. The TheraSpheres ${ }^{\circledR}$ are pre-manufactured with the yttrium- 89 captured in non-toxic glass microspheres $(20-30 \mu \mathrm{m})$, which is bombarded post-manufacture with neutrons to produce yttrium-90 microspheres. This isotope is a $2 \mathrm{MeV}$ beta exclusive emitter with a half-life of 2.7 days, making it ideal for local irradiation of tumours. Since external beam irradiation is insufficient in liver tumours, these spheres are injected intra-arterial and trapped in the vascular system of the tumour to deliver a high local dosage. TheraSpheres ${ }^{\circledR}$ were registered by the FDA under the Humanitarian Device Exemption Guidelines and extensive clinical trials before adoption in clinical practice was therefore not required. An exhaustive number of publications followed (with only some referenced in this article) regarding the safety and efficacy of this invention with the overall consensus that administration with adherence to proper protocol leads to a reasonable effective and non-toxic treatment option. Non-life threatening gastrointestinal complications, lymphoenia without clinical significance, pneumonitis, cholecystitis, acute pancreatitis, radiation dermatitis and gastro-intestinal ulceration was reported in some cases. These side-effects are also reported with resin yttrium-90 microspheres (SIR-Sphere ${ }^{\circledR}$ ) and are related to the irradiation dosage received [129-134]. SIR-Spheres ${ }^{\circledR}$, the second FDA-registered yttrium-90 sphere to reach the stage of clinical use, has a wider particle size distribution $(20-60 \mu \mathrm{m})$ when compared to TheraSphere ${ }^{\circledR}$ technology $(20-30 \mu \mathrm{m})$ and also contains less activity (40-70 Bq per SIR-Sphere ${ }^{\circledR}$ compared to the $2500 \mathrm{~Bq}$ per TheraSphere $\left.{ }^{\circledR}\right)$. SIR-Spheres ${ }^{\circledR}$ are non-degradable plastic resin spheres into which yttrium-90 is incorporated. The possible competitive edge for SIR-Spheres ${ }^{\circledR}$ are a lower activity dosage as well as lower specific gravity compared to the TheraSphere ${ }^{\circledR}$ but this does not clearly translate to more beneficence in clinical practice. The clinical results of SIR-Spheres ${ }^{\circledR}$ demonstrated efficacy and safety equal to TheraSpheres ${ }^{\circledR}$ and the system design allows for the effective containment of yttrium-90 with no leaching [135-139]. Taking into account the limited options available in the treatment of hepatic malignancy, which is an extremely aggressive cancer, radioembolization with either type of yttrium-90 microbeads are a viable choice of agent in the clinical setting. 


\section{Nanoparticles}

Further down the size range, nanotechnology is a rapidly expanding frontier of modern research that even managed to reach notoriety in the common household. These structures can be manufactured from a myriad of materials (including metals in different states, polymers, lipids, and larger biological molecules) as long as their size are restricted to the nanometre range and they exhibit novel properties, different compared to the parent substances [140-142]. Although nanoparticles have great capacity to incorporate different types of imaging and therapeutic entities in one system, development of these agents are hampered by additional intensive investigations required to determine pharmacokinetics, biocompatibility and safety (nanotoxicology) due to the undefined characteristics of these units [143]. The core of the nanoparticle (see Fig. 3 ) must be chosen to provide the needed characteristic. A multimodal imaging agent will for example include a magnetic core for MRI contrast such as iron oxide. Nanoparticles can be functionalized to either target the nanoparticle (with ligands or proteins) or to allow for the addition of a nuclear isotope or tracer. Nanoparticles has been applied to nuclear medicine in the fields of multimodality imaging, theranostics as well as to target the radioisotope for enhancement of localization at the area of interest.

\subsection{Multimodal imaging}

Iron oxide nanoparticles were conjugated with NOTA (1,4,7-triazacyclononane-1,4,7-triacetic acid) to allow radiolabelling with gallium-68 resulting in dual function probes substituted to the functional amine groups of PEG phospholipids. This compound allowed for PET and MRI in mouse xenograft models (Fig. 4) and this system therefore has dual-imaging potential [144]. Dextran coated iron oxide particles can be adapted to permit for the modification of the surfaces of these nanoparticles and allow coupling to PET agents. This method has been successfully applied in iron containing nanoparticles linked with copper-64 for the targeting of vascular inflammation $[145,146]$ and ultra-small paramagnetic iron oxide particles with the ability to bind to various isotopes (zirconium-89, copper-64 and indium-111) [147]. Protein based nanoparticles can also be employed to develop dual-modality imaging agents. MnMEIO (Md-doped magnetism engineered iron oxide) probes were functionalized with serum albumin to provide nanoparticles that can be used as probes for magnetic resonance imaging. To these nanoparticles, iodo-beads (iodine-124) were coupled to provide with dual PET imaging capabilities [148]. In similar research, polyaspartic acid coated iron oxide nanoparticles conjugated with the tripeptide arginine-glycine-aspartic acid (RGD) were synthesized, providing a

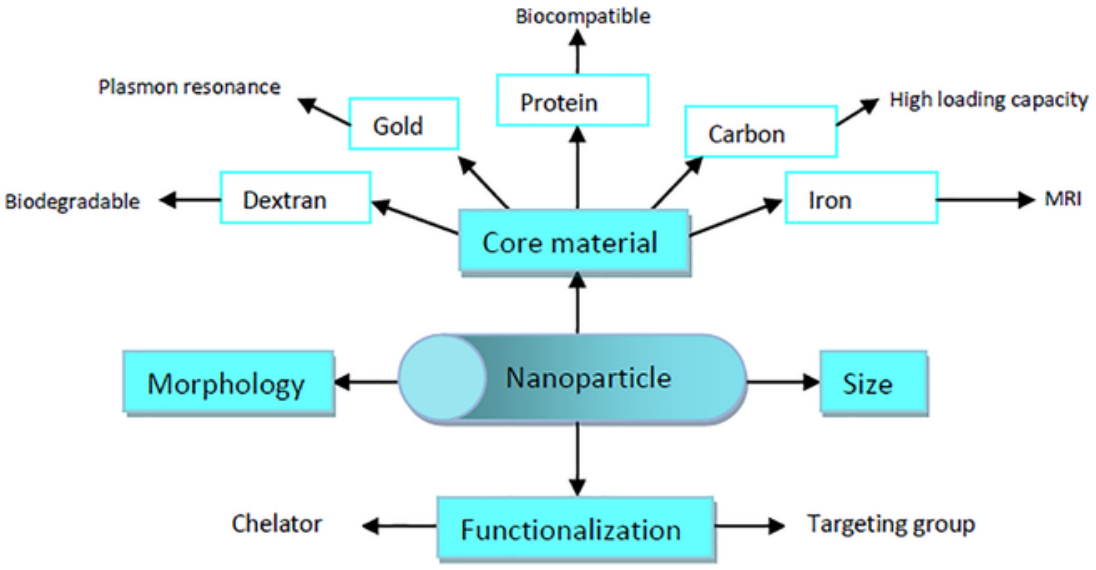

Fig. 3. The various adaptations of nanoparticles as discussed in this review article.

PET image

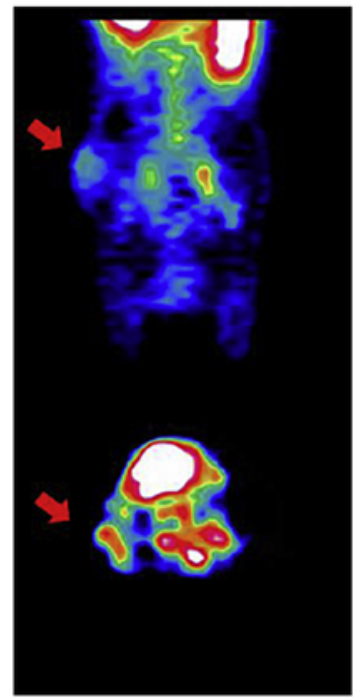

MR image

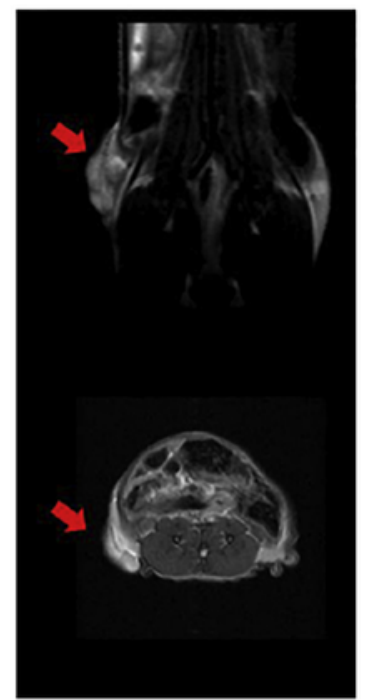

PET/MRI image

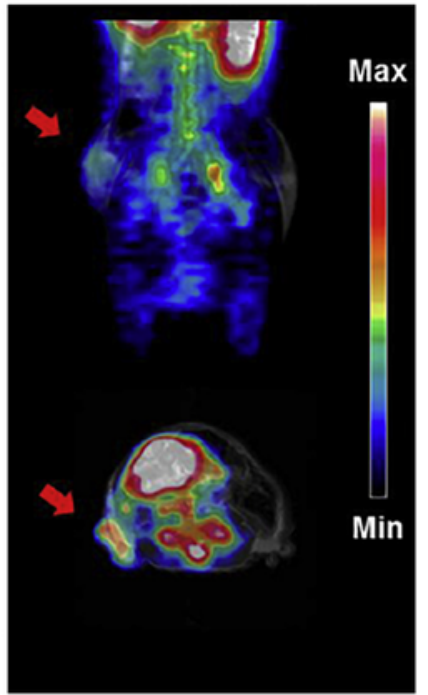

Fig. 4. PET and MR images obtained with ${ }^{68} \mathrm{Ga}-\mathrm{NOTA}-\mathrm{OA}-\mathrm{IONP}$ for tumour diagnosis. Reproduced with permission from the reference [144]. 
nanoparticle platform for coupling with copper-64 for PET imaging as well MRI. This probe showed potential in the detection of tumours that demonstrates integrin expression [149].

Successful imaging of cancers expressing mesothelin was performed in vivo by $\left.{ }^{[111} \mathrm{In}\right] \mathrm{In}-\mathrm{mAbMb}$ conjugated to dextran coated super magnetic iron oxide nanoparticles. These particles also demonstrate the optimal size distribution for their application as dual-SPECT/MRI nanoprobes [150]. In order to allow direct radiolabeling of the supermagnetic iron oxide nanoparticles with a radiolabeled tracer, De Rosales et al. [151] removed the dextran core of commercially available Endorem SPION's and bound ${ }^{99 \mathrm{~m}} \mathrm{Tc}$-alendronate directly to the core of the iron oxide particle. It is envisioned that the bisphosphonate of the radiotracer (alendronate) can be further adapted for SPECT or PET combined with MRI. An even smaller bisphosphonate iron oxide nanoparticle for functionalizing with SPECT agents has been developed [152]. All these nanoparticles have not yet been modified to target specific disease mechanisms and needs further development to allow for clinical use. To target angiogenesis of tumour tissue, Lijowski and colleagues [153] produced nanoparticles containing technetium-99m (for SPECT imaging), gadolinium (for MR imaging) and an $\alpha_{v} \beta_{3}$-integrin antagonist. In vivo testing showed a high targeting of tumours and this probe therefore has the potential to be used for tumour localization with SPECT as well as visualization of tumour vasculature by MRI. Lee and co-workers synthesized supermagnetic iron oxide nanoparticles labelled with technetium-99m and coupled with lactobionic acid to target hepatocytes. In a bio-distribution study these nanoparticles accumulated in liver tissue [154].

To allow for imaging of patients, imaging probes used in optical systems, including multimodal systems, emit in the near-infrared region. Combining the modalities of optical imaging (or optical visualization with dyes) with nuclear imaging has tangible advantages when applied to the mapping of the sentinel lymph node (SLN) during the evaluation of metastasis. Currently in clinical practice a technetium-99m radiotracer is injected into tumour lesions and the SLN (Sentinal Lymph Node, first node draining from the tumour site) is identified with SPECT imaging. Thereafter a dye may be injected into the same tumour site during the surgical procedure to provide optical guidance for the removal of the correct lymph node. The removed lymph nodes are then evaluated for the presence of malignant cells and this predicts the clinical staging of the patient as well as probable life expectancy [155]. The entrapment of a dye in this system has generated scientific interest since simultaneous localization will be of great clinical value [156]. Iron oxide nanoparticles functionalized with technetium- $99 \mathrm{~m}$ is proposed, contributing MRI to the system as well as visualization by black colouring of lymph tissue due to accumulation of iron oxide nanoparticles [157]. Nanoprobes could be synthesized to contain multiple optical imaging agents and radionuclides for application in SLN imaging [158]. Kim et al. [159] developed a PET/MRI/optical nanoprobe with a silica core incorporating a near-infrared dye and gallium-68 with positive in vivo imaging supporting the potential of further clinical application. In the case of SLN imaging, the size of the carrier system is more important than in other applications since smaller particles will be cleared from the injection sites more efficiently, but larger particles will lead to less leakage at the SLN and therefore a balance needs to be found. No exact specifications are found in literature, and trial and error are currently the only way to identify the correct dimensions for each developed carrier system.

One dual PET-optical probe has been determined safe with favourable pharmacokinetic characteristics in a microdose first-in-human investigation. This tracer is composed of inorganic silica nanoparticles (C-dots) combined with iodine-124 for PET imaging, a cyanine (Cy5) dye for fluorescence and cRGDy as targeting peptide for imaging of integrin expressing tumours. This technology can provide PET diagnostics but also allow for image guided surgery $[160,161]$. These C- dot probes can be adapted to target a variety of biological processes and has been proven effective and safe in animal xenografts [162, 163]. Similar silica nanoparticles containing other fluorescent dyes in combination with PET tracers are under investigation. For example a quantum dot core functionalised with DOTA as chelator (to allow for the binding of copper-64 and vascular endothelial growth factor to allow targeting), was determined to be a viable probe for tumour imaging during in vivo studies [164]. The same principle was followed in the development of another probe, coupling quantum dots to copper-64 with the RGD motif to allow for tumour targeting [165].

UCL (up-conversion luminescence) is the ability of a particle to internalize two or more received photons and subsequently emit fluorescent light of high energy that is sufficient for the optical imaging of biological systems. Lanthanides are very popular UCL agents, providing strong enough signals for clinical application. A study investigated the incorporation of samarium-153 into nanoparticles containing a lanthanide but these nanoparticles need optimization since they were mostly accumulated by the liver and spleen in vivo [166].

Cerenkov radiation is the phenomena of the emission of photons by certain radioisotopes whilst decaying. These events can be captured by Cerenkov luminescence imaging (CLI). Cerenkov luminescence is present in certain positron emitters (e.g. fluorine-18, copper-64, zirconium-89, iodine-124), beta emitters (iodine-131) as well as alpha emitters (actinium-225) $[167,168]$. To allow for the emission of Cerenkov radiation, the isotope should have a minimum beta energy yield of 263 $\mathrm{keV}$ [169]. To allow for the production of an image, these events need to be propagated additionally since Cerenkov luminescence is absorbed by the tissue surrounding these probes. A possible strategy for CLI is to convert this radiation to fluorescence and this was done successfully by utilization of europium oxide nanoparticles. This is an example where near infrared emitting nanophosphors are activated, not by outside applied energy, but from photons originating from nuclear isotopes incorporated in the same nanoparticle. Other lanthanide containing nanoparticles can exhibit similar ability, as well as noble metal nanoclusters [170-173]. A study evaluating the CLI provided by gold-198 incorporated in gold nanocages, provided evidence of in vivo efficacy to image breast cancer xenografts with this noble metal system optimizing its own luminescence [174]. Quantum dots can also be activated by internal radiation to produce fluorescence for the imaging of biological systems and can therefore be utilized as a carrier system for multi-modal imaging [175].

To combine PET, MR and fluorescence molecular tomography, a radioisotope modified trimodal nanoparticle $\left[{ }^{18} \mathrm{~F}\right] \mathrm{F}$-CLIO was developed. This nanoparticle that has a dextran and superparamagnetic iron core and was labelled with fluorine-18 by the so called "click" chemistry. This system is biodegradable in vivo, and no long-term toxicities are envisioned for these agents, but extensive biological evaluations are necessary [176]. Xie et al. developed a trimodal PET/MR/optical nanoprobe with iron oxide nanoparticles functionalized by dopamine to afford the incorporation of other probes $\left(\left[{ }^{64} \mathrm{Cu}\right] \mathrm{Cu}-\mathrm{DOTA}\right.$ and Cy5.5). Substantial accumulation at tumour sites was recorded with low accumulation by macrophages which show promise for the clinical use thereof [177]. Yang et al. combined gold and iron-oxide to form a nanoparticle functionalized with copper-64 and a targeting affibody providing a trimodal tumour targeting imaging agent [178]. The use of porphyrins to manufacture copper-64 containing nanoparticles (porphyrosomes) results in a dual-modality probe since porphyrin exhibits intrinsic fluorescence with in vivo efficacy for applications in prostate cancer and imaging of micro-metastases [179, 180].

UCL can be combined with PET and MR to add high sensitivity and spatial resolution to the system but negate the limited penetration normally provided by fluorescence. Various lanthanides (gadolinium- $3^{+}$, ytterbium $-3^{+}$and erbium $-3^{+}$) were combined with fluorine- 18 as PET agent in nanophosphors $\left(\mathrm{NaYF}_{4}\right)$. The incorporation of gadolinium af- 
forded magnetic properties for MRI. The in vivo evaluation provided optimal results for both ultra-sensitive investigations on a molecular level as well as whole-body evaluation [181]. Other manufactured UCL/PET/ MRI nanophosphors incorporating lanthanides was developed to contain iodine-124 and also provides tumour specificity [182].

\subsection{Theranostics and radioimmunotherapy}

Gold nanoparticles have also been implemented to stabilize and allow the targeting of various isotopes including copper-64 and iodine-125. In vivo imaging efficacy of alloyed gold nanoparticles containing copper-64 was demonstrated for tumour cells in a mouse breast cancer model. Targeting of radioimmuno-gold-nanoparticles to lung cancer tissue was achieved in vivo by the labelling of gold nanoparticles with the cetuximab antibody and iodine-131. Additionally, gold nanoparticles can be excited through the surface plasmon resonance phenomenon to produce photo-thermal heating locally thereby destroying the cancer cells. The theranostic capabilities of a PET agent combined with gold nanoparticles will therefore allow for imaging of the accumulation of these particles at the tumour site and activation thereof at the most opportune moment for therapy. Animal xenograft studies have confirmed the potential of such an application [183-186, 194]. Gold nanorods labelled with iodine- 125 have been developed for the imaging of infection and inflammation but is yet to be applied as a theranostic agent [187]. Another study investigates only the therapeutic application and not the diagnostic, use of radioactive gold-198 nanoparticles for thermoablation [188]. This has been investigated for prostate tumours as well as liver neoplasms with success demonstrated in vivo. A stable gold-198 nanoparticle containing mangiferin was developed from a phytochemical origin. This unique approach to a more environmentally conscious application of nanotechnology is worth mentioning since this allows the reduction of the gold precursor to nanoparticles without the use of additional toxic reducing agents. During the in vivo evaluation no toxicity was found in the animals and a five-fold reduction in tumour volume over three weeks was demonstrated $[189,190]$.

Photo-thermal agents have the ability to convert externally applied electromagnetic radiation to release heat that destroys target cells in the vicinity of the molecule. The combination of such a nanoparticle with a radiopharmaceutical provides the ability to monitor the distribution inside the patient and monitor biodistribution before the external electromagnetic energy is applied. DeNardo et al. [191] synthesized an iron oxide nanoparticle linked with a mAb L6 analogue and indium-111 for scintigraphy imaging as a breast cancer theranostic. Xenograft studies in mice showed accumulation at the target site as well as subsequent tumour growth delay but acute animal deaths were present in some test groups. For combination of PET with photothermal ablation therapy, copper-64 containing copper monosulfide nanoparticles were synthesized. These nanoparticles are distributed by passive accumulation to the tumour site and absorb near-infrared light. In vivo efficacy was verified in glioblastoma xenografts [192]. It is however notoriously difficult to convert results from xenograft animal models to human efficacy due to different blood diffusion rates and biodistribution to organs. It is therefore important that thorough clinical investigations are performed and side-effects are reported meticulously before the technology is evaluated as unfeasible or indeed viable. Furthermore, since in vivo studies are the mainstay of pre-clinical evaluation, adverse-events or deaths in animals needs to be seen as serious indicators of failure, even though these might not be present in humans. Until better predictors of toxicity exist (especially for nano-technology), animal data are high indicators of the future of the invention under investigation.

Another example is lutetium-177 labelled cerasome nanoparticles that entrap indocyanine green to enable optical imaging (NIRF), nuclear imaging as well as photothermal ablation of tumours [193]. Wu et al. synthesized lutetium-177 phosphate nanoparticles with apoferritin as core with the aim of providing an agent suitable for RIT that allows for imaging as well. The apoferritin core can be functionalized with different mAb antibodies to target tumour cells [194].

Radioimmunoconjugates can also be combined with magnetic nanoparticles which can then be localized to tumour sites with external magnetic fields during clinical use. An example of this is an iodine-131-anti-vascular endothelial growth factor $\mathrm{mAb}$ that is combined with magnetized dextran nanoparticles. This technology provides tumour reduction in vivo with no bone marrow suppression present [195]. Our search did not uncover any drug carrier systems containing an RIT agent that has been clinically evaluated in humans to date. These systems rely on the active targeting provided by an outside source (mAb or magnetic field) to localize the nuclear isotope to the area of interest rather than passive targeting inherent to the system itself. Overall, active targeting provides more control over the distribution of the isotope than demonstrated with passive targeting.

\subsection{Targeted nanoparticles for imaging}

Carbon nanotubes are one of the most scientifically valued nanostructures due to a variety of applications based on the physical strength of this material. This system has an above average electrical and thermal conductivity, an ordered structure, is highly elastic and flexible while at the same time exhibiting considerable strength and a high surface area. It is made of interconnected benzene rings forming a sheet-like structure that is rolled into a tube. This system is categorized into the carbon allotropic category of fullerenes. There are two types of structures namely single walled (SWNT) that has one rolled up sheet of carbon and is a smaller sized tube, and multi-walled (MWNT) which contains multiple rolled up sheets. Carbon nanotubes have a unique contribution to drug delivery because this system does not illicit an immune reaction when introduced into biological systems. This system is also very adaptable to incorporate various entities but is hampered by its hydrophobic nature which commands the need for surface modification to allow for biological applications [196-198]. Ruggiero et al. [199] report a SWNT made from carbon that utilize radiometal-ion chelates to allow better solubility and coupling to radioisotopes whilst simultaneously incorporating an antibody (E4G10) to target tumour vasculature. It was demonstrated that chelators 1,4,7,10-tetraazacyclododecane-1,4,7,10-tetraacetic acid (DOTA) and desferrioxamine B (DFO B) increased solubility of the SWNT substantially so that biological application is feasible. Due to the high increase in blood vessel formation of tumour tissue, these tissues exhibit a high number of structural errors which include expression of the monomeric vascular endothelial-cadherin epitope on epithelial cells to which the antibody E4G10 binds exclusively. The carbon tubes are therefore targeted to tumour vasculature by this antibody where the radioisotope is then subsequently delivered. For PET imaging zirconium-89 is coupled to the SWNT and for therapy following imaging the zirconium- 89 can be substituted with the alpha particle-emitting actinium-225 to deliver highly concentrated ionizing radiation. This system showed high efficacy and a profitable safety profile in in vivo animal studies and is currently under investigation for clinical use [199]. Other tumour xenograft studies on carbon nanotubes coupled to radioisotopes involved copper-64 and indium-111. In general it was determined that carbon nanotubes clear rapidly from the blood pool to the target area and have ideal qualities as a drug carrier system for radiotheranostic agents $[200,201]$.

Nanoparticles were also evaluated for the possibility of imaging infection and/or inflammation. Macrophage targeting dextran nanoparticles containing fluorine-18 or zirconium- 89 also provided in vivo efficacy to detect local inflammation but no data regarding the imaging of infection was provided [202, 203]. 


\subsection{Nanoparticles for alpha therapy}

Actinium-225 was successfully incorporated into lanthanum phosphate nanoparticles (coupled to mAb for targeting) and in vivo targeting efficacy was established. The system was further optimized to reduce the leakage of daughter isotopes and reduce possible toxicity [204, 205]. Since a preparation containing radium-233 has been approved by the FDA (Xofigo ${ }^{\circledR}$ ), the optimization of this alpha-emitter is also under investigation. This isotope demonstrates distinct advantages over actinium-225 such as higher availability (a actinium-227/radium-233 generator is more accessible) as well as a lower amount of daughter isotopes being released by the target cells due to their very short half-life - lasting seconds. Current research regarding incorporation of this isotope in drug delivery systems is focused on developing a stable complex agent and no in vitro evaluations are available at this stage. Systems under evaluation include iron oxide nanoparticles, nanozeolite bioconjugates, hydroxyapatite particles and lanthanum phosphate nanoparticles [206-210].

\section{Other drug carrier systems applied to nuclear medicine}

Micelles are also being explored as possible carriers for dual nuclear-optical imaging probes, with all published studies demonstrating both probes coinciding at tumour tissue [211, 212]. A micelle has been developed that can harness the ability of quantum dots to generate light for the activation of a cisplatin pro-drug (also incorporated in the micelle) resulting in targeted chemotherapy. Furthermore, the quantum dots also add heat induction for photodynamic cancer therapy and the generation of singlet oxygen as two additional cancer treating mechanisms. Finally, technetium-99m is incorporated as SPECT component to provide nuclear imaging additionally to the optical imaging provided by the quantum dots [213]. If this probe can progress to clinical usage it will provide not only a three-pronged therapeutic attack, but also a dual imaging modality.

In order to allow for the administration of radiotracers by the oral route of administration rather than the traditional intravenous route, Grobler and Zeevaart [214] patented a formulation, entrapping radiotracers in Pheroid ${ }^{\circledR}$ technology. The system is a nano- or micro-emulsion and Pheroid $\AA$ vesicles possess a lipid bilayer but cannot be grouped under the traditional liposomes due lack of a phospholipid or cholesterol component. While the unformulated [99m Tc]Tc-MDP (technetium-99m-methyl diphosphonate) radiotracer offered no absorption out of the gastro-intestinal tract during the in vivo evaluations, the [ ${ }^{99 \mathrm{~m} T c]}$ Tc-MDP formulated in Pheroid ${ }^{\circledR}$ provided blood circulation levels comparable to that obtained after the gold standard $\left[{ }^{99 \mathrm{~m}} \mathrm{Tc}\right] \mathrm{Tc}-\mathrm{MDP}$ intravenous injections (Fig. 5). This technology enables the oral administration of radiotracers that can reduce stress in paediatrics, patients receiving multiple nuclear imaging procedures, patients that fears needles and patients with collapsed arteries. Clinical evaluation still needs to be performed. The Pheroid ${ }^{\circledR}$ employs passive entrapment. Active entrapment is however another possibility that can be explored to enhance clinical efficacy.

\section{Discussion}

\subsection{Current challenges}

Exciting preclinical work in this field rarely seems to reach clinical translation and this is a concerning trend (Table 2). Therefore, the most important current challenge is the translation of the vast number of in vivo success studies to clinical use. Similar alarm is expressed in other fields where drug carrier systems are applied as is evident in literature reviews on non-nuclear applications. Some of the reasons provided in literature are the difficulty of up-scaling complex manufacturing processes associated with these systems, additional costs regarding quality assurance, resistance offered by government regulatory boards, lengthy registration processes as well as intellectual property challenges [215-218]. It is our opinion that a lack of understanding of the complex interactions of these novel technologies with the biological environment and incorporated nuclear agents also leads to under optimization making them fall short of their potential.

\subsection{Limitations to successful application of drug delivery systems to nuclear medicine}

Although the vast amount of preclinical work did not directly translate to clinical usability, literature contributes hugely to the broad understanding of these systems by the scientific community. In order to define the ideal characteristics of a drug carrier system for it to succeed in contributing positively to nuclear medicine, it is necessary to consider both the limitations dictated by the radiotracer as well as those contributed by the characteristics of the drug carrier system itself.

We therefore propose some limitations (Fig. 6) for an ideal drug carrier system if it is to be utilized to deliverer radiopharmaceuticals.

\section{a) Particle size}

- The drug carrier system size needs to be restricted to less than 400 $\mathrm{nm}$ otherwise the system will be removed from the blood circulation by the reticular endothelial systems before it can accumulate at the

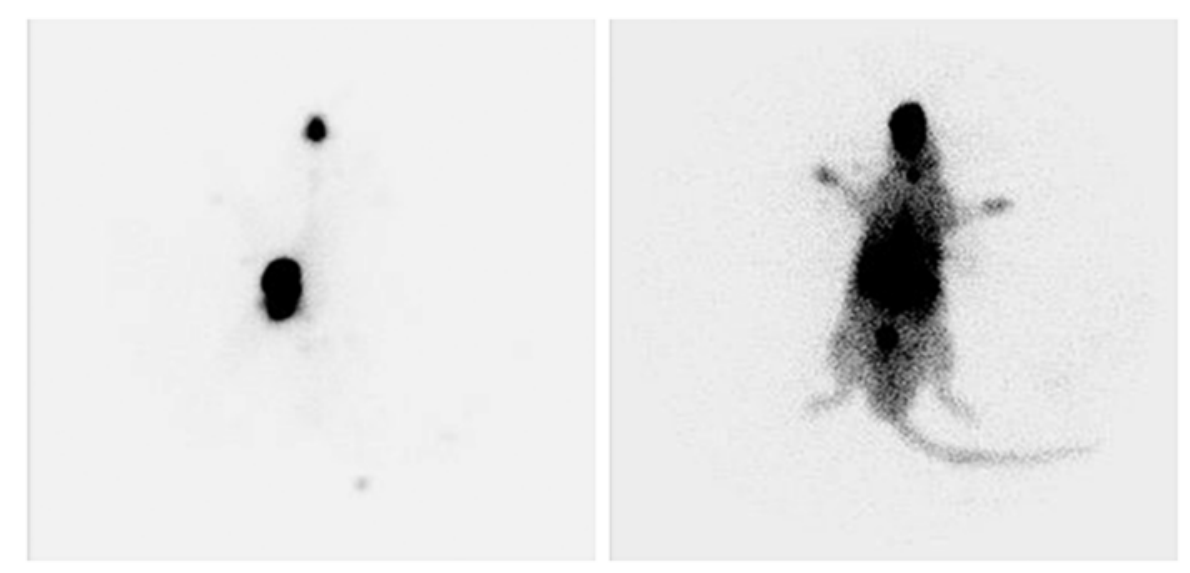

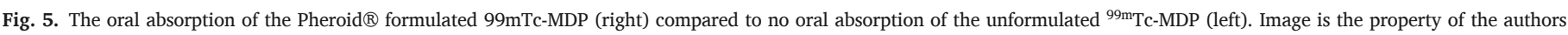
[214]. 
Table 2

Current research on the utilization of drug delivery systems in nuclear medicine.

\begin{tabular}{|c|c|c|c|c|}
\hline & $\begin{array}{l}\text { Therapeutic nuclear } \\
\text { medicine }\end{array}$ & $\begin{array}{l}\text { Theranostics (imaging }+ \\
\text { treatment) }\end{array}$ & Multimodality imaging & $\begin{array}{l}\text { Enhancement of } \\
\text { pharmacokinetics }\end{array}$ \\
\hline $\begin{array}{l}\text { Development } \\
\text { phase }\end{array}$ & $\begin{array}{l}\text { (1)Actinium-225 liposomes } \\
\text { and polymersomes (alpha } \\
\text { emitter) [Section 2.5] } \\
\text { (2Radium-233 nanoparticles } \\
\text { (alpha emitter) [Section 4.5] } \\
\text { (3Radioimmunotherapy } \\
\text { [Section 2.7] }\end{array}$ & & & \\
\hline $\begin{array}{l}\text { Preclinical } \\
\text { phase }\end{array}$ & $\begin{array}{l}\text { (1)Actinium-225 liposomes } \\
\text { (alpha emitter) [Section 2.5] }\end{array}$ & $\begin{array}{l}\text { (1)Rhenium-188 nanoparticles } \\
\text { (beta \& gamma emitter) and } \\
\text { microspheres [Section 2.1] } \\
\text { (2) Radiochemotherapeutics } \\
\text { [Section 2.4] } \\
\text { (3Technetium-99m anti-TB } \\
\text { rifampicin \& ofloxacin [Section } \\
2.1 \text { ] } \\
\text { (4Thermal ablation gold } \\
\text { nanoparticles with copper-64 and } \\
\text { 125I [Section 4.2] } \\
\text { (5)Multimodal imaging } \\
\text { theranostics [Section 2.3] }\end{array}$ & $\begin{array}{l}\text { (1)Liposomes for PET/MRI; Liposomes for } \\
\text { PET/optical; SLN imaging liposomes } \\
\text { [Section 2.2] } \\
\text { (2Nanoparticles for PET/MRI ; SPECT/ } \\
\text { MRI ; PET/optical; SPECT/optical; SLN } \\
\text { imaging [Section 4.1] } \\
\text { (Micelles for PET/optical [Section 5] }\end{array}$ & $\begin{array}{l}\text { (1) Neurological imaging } \\
\text { [Section 2.10] } \\
\text { (2)Technetium-99m infection } \\
\text { and inflammation imaging } \\
\text { [Section 2.8] } \\
\text { (3Nanoparticles PET } \\
\text { imaging infection and } \\
\text { inflammation [Section 4.3] } \\
\text { (4Distinguishing } \\
\text { inflammation from } \\
\text { infection [Section 2.8] } \\
\text { (5) Technetium-99m } \\
\text { liposome blood pool } \\
\text { imaging [Section 2.9] } \\
\text { (6Increased stability of } \\
\text { labelled tracer with } \\
\text { liposomes [Section 2.11] } \\
\text { (PET tracer targeting with } \\
\text { nanoparticles [Section 4.3] } \\
\text { (1) Oral administration of } \\
\text { tracers [Section 5] }\end{array}$ \\
\hline $\begin{array}{l}\text { Clinical trial } \\
\text { phase }\end{array}$ & & $\begin{array}{l}\text { (1)Rhenium-188-BMEDA liposomes } \\
\text { [Section 2.1] } \\
\text { (2Zirconium-89/Actinium-225 } \\
\text { nanoparticles [Section 4.1] }\end{array}$ & & $\begin{array}{l}\text { (1)Targeting tracers with } \\
\text { stealth liposomes [Section } \\
2.6 \text { ] }\end{array}$ \\
\hline Clinical use & $\begin{array}{l}\text { (1) Yttrium-90 TheraSpheres } \\
\text { or SIR-Spheres (beta emitter) } \\
\text { [Section 3.1] }\end{array}$ & & & \\
\hline
\end{tabular}

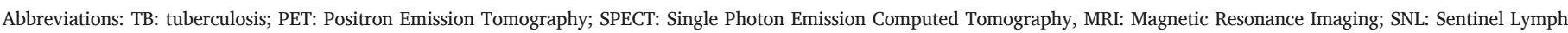
Node.

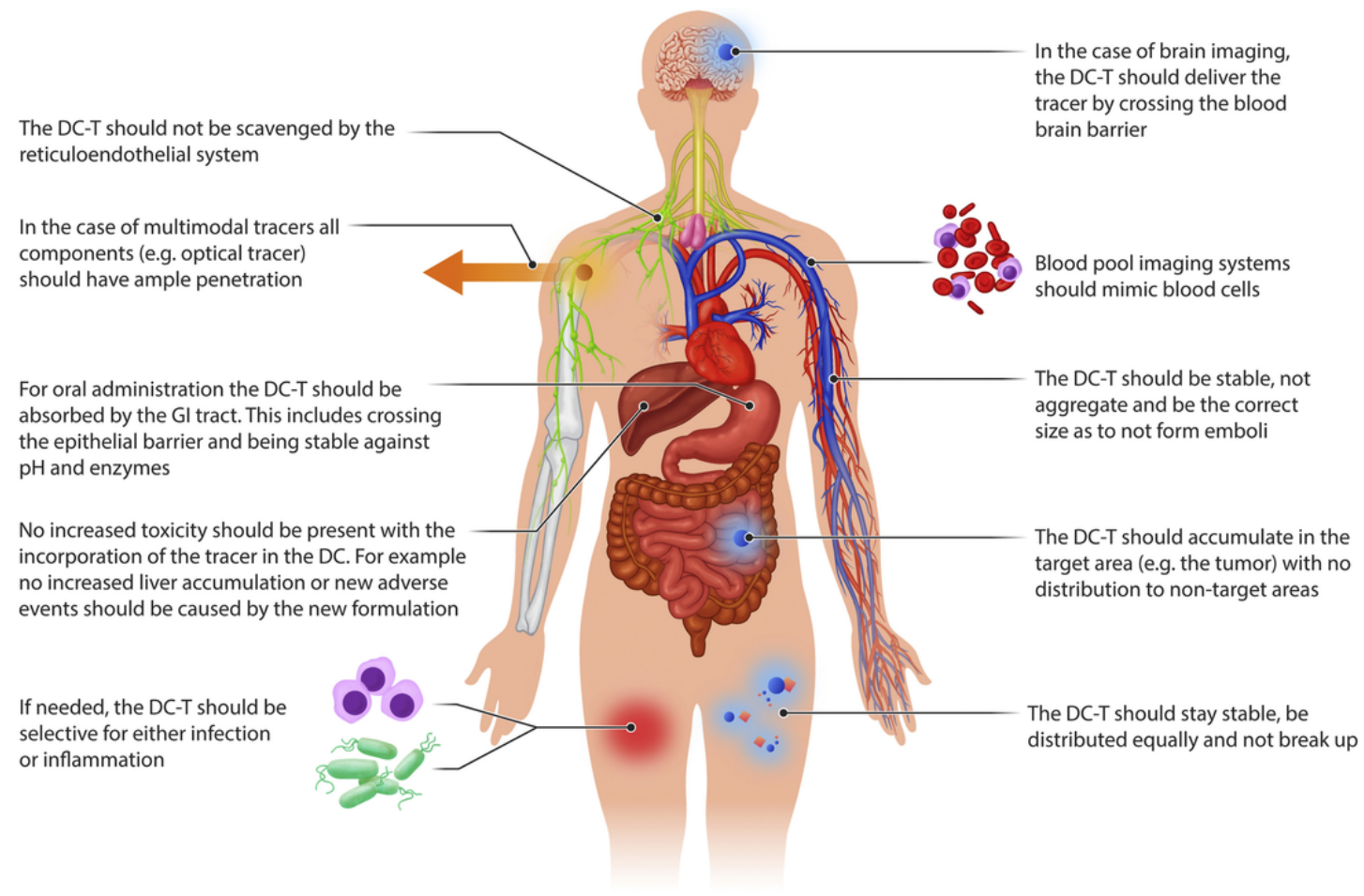

Fig. 6. A summary of the suggested characteristics a successful drug delivery system should possess (DC-T = drug carrier and tracer complex). 
target site [219]. Recently it is believed that this should be even smaller to mimic the size of antibodies $10-35 \mathrm{~nm}$.

- If however, the enhanced permeability and retention effect (EPR) associated with tumour vasculature, inflammation and other lesions is to be used for passive accumulation, macromolecules with high molecular weights (between 10 and $500 \mathrm{~nm}$ and restricted below $80 \mathrm{kDa}$ ) should be used and the drug delivery system should contribute to increase the size of the radiotracer [220]. Sonoporation (using combined ultrasonification and microbubbles) is able to enhance the EPR effect for particles on the larger side of the spectrum and this technique could also be employed if necessary [221].

\section{b) Stability}

- The system should be stable and not leach isotopes at unspecific areas. Premature release (called "burst release") is unacceptable and the carrier system should only release its load at the target site [222]. Neither should it release recoiled daughter isotopes and be able to with stand the recoil energies for instance of alpha decay.

- The drug carrier system and the radiopharmaceutical should be coordinated in such a way that the radiotracer is delivered at the target site in a manner providing accumulation of such an amount to allow imaging/therapeutic activity within the constraints of the decay half-life of the isotope in question

- The drug delivery system should be stable during in the blood circulation and not aggregate since particles larger than $5 \mu \mathrm{m}$ can cause emboli and cardiovascular events

- Once the drug carrier system reach the target site, the radiopharmaceutical should be released efficiently and effectively to ensure high therapeutic action. If the drug carrier system fails to release the on-site, the whole aim of the system fails [223]. This is of course not necessary for diagnostic radiopharmaceuticals where the radionuclide can stay within the delivery system as long as the latter has reached the target site as the resolution of the imaging is in any case only 2-8 $\mathrm{mm}$.

\section{c) Surface charge}

- A negative surface charge of particles reduces removal by the reticular endothelial systems and this should therefore be taken into account during the development of the drug carrier system [224, 225]

- If the surface charge is overtly negative they can have the tendency to accumulate in the liver. It is therefore important to strike a balance between the surface charge and the excretion functions of the body [226]

\section{d) Physiological acceptability}

- In active targeting, the ligands (e.g. antibodies) used to target the drug carrier system and entrapped radiotracer should not illicit adverse events in the biological system

- The components of which the drug carrier system is manufactured should be Generally Regarded as Safe

- The drug carrier system should not increase the toxicity of the radiotracer due to changes in biodistribution. An example of increased side-effects in conventional pharmaceuticals is the additional side-effect of hand-foot syndrome when doxorubicin is delivered with liposomes. This was attributed to the extended circulation of the drug in the bloodstream resulting in a higher delivery of the drug to the skin surface [226]

- Drug delivery vehicles that fail to deliver their radiotracer load at the target site should be removed and excreted effectively since undelivered tracer can reduce image quality or expose the patient to higher radiation levels
- A combination of two entities (e.g. radiotracer and a chemotherapeutic agent) should be compatible

- A complete understanding of the drug carrier system's biodistribution, toxicity and pharmacokinetics is essential [227]. Furthermore, the available adaptations to the system as well as the biological effects should be quantified so that the system can be tailor-made for the radiotracer that needs to be delivered. Before all the basic characterization of the drug delivery system is not complete, it should therefore not be attempted to utilize it for clinical application in the field of nuclear medicine

- Biological constraints imposed by the target site should be kept in mind when formulating radiotracers into drug carrier systems. For example, if the blood brain barrier needs to be crossed, the drug delivery system should adhere to the specifications that will allow it to carry the radiotracer across this biological barrier [228]

- Radiotracer pharmacokinetics and decay rate need to be compatible with the drug delivery system and the biological effect longed for [223]

\subsection{Future perspectives of drug delivery systems in nuclear medicine}

Since the time Paul Ehrlich famously kicked off the search for the "magic bullet" to treat diseases effectively and efficiently, the progress of drug delivery systems can be described as slow but sure. It is evident from literature that there is a general disillusionment regarding the outcomes obtained from liposome research when the efforts and economic investments in this area of research are evaluated. The delivery of pharmaceutical active ingredients by nanoparticles also lacks clinical translation with the failure of most of these agents to accumulate at the target site in therapeutic quantities and not distribute to other tissue [229-231]. It is however important to realize that every failed development does still contribute to the understanding of these systems and the characteristics that negatively impact biological effectiveness.

Cell mediated drug delivery is a very promising area of drug delivery systems that might be investigated in the future for the delivery of radiopharmaceuticals. These systems use specific cells loaded with the pharmaceutical (or in this case radiotracer) and since the cells retain their function, their distribution will mimic their natural movement to disease areas. The cells adapted with this method include for instance red blood cells, leukocytes and - more recently- stem cells. These carrier systems have advantages over artificially produced systems including well known biodistribution behaviours, reduced side effects as well as reduced clearance by the reticuloendothelial systems [232]. Various other nanoparticulate delivery systems exists (e.g. dendrimers, virosomes) with only the systems already applied in nuclear medicine, discussed in this review. If these novel systems exhibits biological behaviours that can positively contribute to nuclear medicine goals, it is important to investigate such applications.

The funding for nanotechnology products for all applications is ample with the National Nanotechnology Initiative of the United States contributing $\$ 1.5$ billion per year and the private sector even more than that [233]. Although this budget is targeted at research and development in general (with $\$ 400$ million dollars dedicated to health research in 2011), the investigation of the properties of these technologies can be applied not only in the field of research, but also be translated to the health sector [234]. Currently this field progress through trial and error and with the vast number of literature publications regarding the behaviour of these systems as well as economic investment therein the future does look promising. It is therefore not a question of "if", but rather of "when" the rewards for the vast amount of investment and research will start to provide benefits in quick succession. 


\section{Conclusion}

Drug delivery systems have great potential when applied to nuclear medicine as is evident by the application of Ytrrium-90 microspheres and Indium-111 liposomes. These technologies have however a vast tract record of research substantiating their use and it is necessary that all drug delivery systems should be investigated completely in order to also obtain successful utilization. In this review we aimed to increase awareness of the possibilities that can be afforded by drug delivery systems and we also introduced some preliminary suggestions regarding limitations that should be taken into account.

\section{Conflicts of interest}

The authors declare that they have no conflict of interest.

\section{Acknowledgements}

J. Kleynhans received financial assistance from the National Research Foundation (NRF) of South Africa (grant number SFH 14070573914) as well as the Nuclear Technologies in Medicine and Biosciences Initiative (NTeMBI)- a national technology platform developed and managed by the South African Nuclear Energy Corporation (Necsa) and funded by the Department of Science and Technology. Opinions expressed and conclusions arrived at, are those of the authors and are not necessarily to be attributed to the NRF and NTeMBI. Hester Oosthuizen is thanked for the manuscript's scientific editing. The graphics (Abstract, Figs. 1 and 3) in this article was drawn by scientific illustrator Christina Sala Ripoll www.cristinasalaripoll.com).

\section{References}

[1] R. Chess, Economics of drug delivery, Pharm. Res. 15 (1998) 172-174.

[2] F. Knauf, P.S. Aronson, ESRD as a window into America's cost crisis in health care, J. Am. Soc. Nephrol. 20 (2009) 2093-2097.

[3] M. Karanikolos, P. Mladovsky, J. Cylus, S. Thomson, S. Basu, D. Stuckler, et al., Financial crisis, austerity, and health in Europe, Lancet 381 (2013) 1323-1331.

[4] S.M. Paul, D.S. Mytelka, C.T. Dunwiddie, C.C. Persinger, B.H. Munos, S.R. Lindborg, et al., How to improve R \& D productivity: the pharmaceutical industry's grand challenge, Nat. Rev. Drug Discov. 9 (2010) 203-214.

[5] J.W. Schannell, A. Blanckley, H. Boldon, Warrington, Diagnosing the decline in pharmaceutical R \& D efficiency, Nat. Rev. Drug Discov. 11 (2012) 191-200.

[6] M.S. Kinch, E. Patridge, M. Plummer, D. Hoyer, An analysis of FDA-approved drugs for infectious disease: antibacterial agents, Drug Discov. Today 19 (2014) 1283-1287.

[7] E. Bettiol, J.D. Wetherington, N. Schmitt, S. Harbarth, COMBACTE Consortium, Challenges and solutions for clinical development of new antibacterial agents: results of a survey among pharmaceutical industry professionals, Antimicrob. Agents Ch. 59 (2015) 3695-3699.

[8] T.M. Allen, P.R. Cullis, Drug delivery systems: entering the mainstream, Science 303 (2004) 1818-1822.

[9] N. Mishra, P. Pant, A. Porwal, J. Jaiswal, M.A. Samad, S. Tiwari, Targeted drug delivery: a review, Am. J. Pharmatech. Res. 6 (2016) 1-24.

[10] L. Sercombe, T. Veerati, F. Moheimani, S.Y. Wu, A.K. Sood, S. Hua, Advances and challenges of liposome assisted drug delivery, Front. Pharmacol. 6 (2015) 1-13.

[11] C. Zylberberg, S. Matosevic, Pharmaceutical liposomal drug delivery: a review of new delivery systems and a look at the regulatory landscape, Drug Deliv. 23 (2016) 3319-3329.

[12] C.A. Batista, R.G. Larson, N.A. Kotov, Nonadditivity of nanoparticle interaction, Science 350 (2015) 1242477

[13] K. Sahil, M. Akanksha, S. Premjeet, A. Bilandi, B. Kapoor, Microsphere: a review, Int. J. Res. Pharm. Chem. 1 (2011) 1184-1189.

[14] J.F. Valliant, A bridge not too far: linking disciplines through molecular imaging probes, J. Nucl. Med. Tech. 44 (2016) 176-183.

[15] W.L. Duvall, L.B. Croft, E.S. Ginsberg, A.J. Einstein, K.A. Guma, T. George, et al., Reduced isotope dose and imaging time with a high-efficiency CZT SPECT camera, J. Nucl. Cardiol. 18 (2011) 847-857.

[16] R. Galea, C. Ross, R.G. Wells, Reduce, reuse and recycle: a green solution to Canada's medical isotope shortage, Appl. Radiat. Isot. 87 (2014) 148-151.

[17] S.A. Hoedl, W.D. Updegraff, The production of medical isotopes without nuclear reactors or uranium enrichment, Sci. Global Security 23 (2015) 121-125.

[18] S.S. Kelkar, T.M. Reineke, Theranostics: combining imaging and therapy, Bioconjug. Chem. 22 (2011) 1879-1903.

[19] T.H. Kim, S. Lee, X. Chen, Nanotheranostics for personalized medicine, Expert. Rev. Mol. Diagn. 13 (2013) 257-269.
[20] A. Kaul, S. Chaturvedi, A. Attri, M. Kalra, A.K. Mishra, Targeted theranostic liposomes: rifampicin and ofloxacin loaded pegylated liposomes for theranostic application in mycobacterial infections, RSC Adv. 6 (2016) 28919-28926.

[21] S.-J. Wang, W.-J. Lin, M.-N. Chen, C.-S. Chi, J.-T. Chen, W.-L. Ho, et al., Intratumoral injection of rhenium-188 microspheres into an animal model of hepatoma, J. Nucl. Med. 39 (1998) 1752-1757.

[22] G. Wunderlich, J. Pinkert, M. Stintz, J. Kotzerke, Labelling and biodistribution of different particle materials for radioembolization therapy with ${ }^{188} \mathrm{Re}$, Appl. Radiat. Isot. 62 (2005) 745-750.

[23] S.C. Blankespoor, X. Wu, J.K. Kalki, H.R. Brown, H.R. Tang, C.E. Cann, et al., Attenuation correction of SPECT using $\mathrm{x}$-ray CT on an Emission-Transmission CT System: myocardial perfusion assessment, IEEE T Nucl. Sci. 43 (1996) 2263-2274.

[24] Y. Shao, S.R. Cherry, K. Farahani, K. Meadors, S.B. Siegel, R.W. Silwerman, et al., Simultaneous PET and MR imaging, Phys. Med. Biol. 42 (1997) 1965-1970.

[25] T. Beyer, D.W. Townsend, T. Burn, P.E. Kinahan, M. Charron, R. Roddy, et al., A combined PET/CT scanner for clinical oncology, J. Nucl. Med. 41 (2000) 1369-1379.

[26] D.W. Townsend, Dual-modality imaging: combining anatomy and function, J. Nucl. Med. 49 (2008) 938-955.

[27] J. Czernin, M. Allen-Auerbach, H.R. Schelbert, Improvements in cancer staging with PET/CT: literature-based evidence as of September 2006, J. Nucl. Med. 48 (2007) 78S-88S.

[28] M.S. Judenhofer, H.F. Wehrl, D.F. Newport, C. Catana, S.B. Siegel, M. Becker, et al., Simultaneous PET-MRI: a new approach for functional and morphological imaging, Nat. Med. 14 (2008) 459-465.

[29] J. Cheon, J.H. Lee, Synergistically integrated nanoparticles as multimodal probes for nanobiotechnology, Acc. Chem. Res. 41 (2008) 1630-1640.

[30] H.F. Wehrl, A.W. Sauter, M.S. Judenhofer, B.J. Pichler, Combined PET/MR imaging - technology and applications, Tech. Cancer Res. Treat. 9 (2010) 5-20.

[31] G. Delso, S. Füst, B. Jakoby, R. Ladebeck, C. Ganter, S.G. Nekolla, et al., Performance measurements of the Siemens mMR integrated whole-body PET/MR scanner, J. Nucl. Med. 52 (2011) 1914-1922.

[32] I.-C. Tan, C. Darne, Y. Lu, S. Yan, A. Smith, J. Rasmussen, et al., Hybrid fluorescence, PET, and CT for small animal imaging, J. Nucl. Med. 53 (2012) 493.

[33] S.R. Cherry, Multimodality imaging: Beyond PET/CT and SPECT/CT, Semin. Nucl. Med. 39 (2009) 348-353.

[34] A.L.B. De Barros, A. Tsourkas, B. Saboury, V.N. Cardoso, A. Alavi, Emerging role of radiolabeled nanoparticles as an effective diagnostic technique, EJNMMI Res. 2 (2012) 39.

[35] B.I. Kharisov, O.V. Kharissova, S.S. Berdonosov, Radioactive nanoparticles and their main applications: recent advances, Rec. Pat. Nanotechnol. 8 (2014) 79-96.

[36] S.S. Davis, J.G. Hardy, S.P. Newman, I.R. Wilding, Gamma scintigraphy in the evaluation of pharmaceutical dosage forms, EJNMMI 19 (1992) 971-986.

[37] W.T. Phillips, A.S. Rudolph, B. Goins, J.H. Timmons, R. Klipper, R. Blumhardt, A simple method for producing a technetium-99m-labeled liposome which is stable in vivo, Nucl. Med. Biol. 19 (1992) 539-547.

[38] J.S. Folwer, N.D. Volkow, G.J. Wang, Y.S. Ding, S.L. Dewey, PET and drug research and development, J. Nucl. Med. 40 (1999) 1154-1163.

[39] B. Goins, R. Klipper, A.S. Rudolph, R.O. Cliff, R. Blumhardt, W.T. Phillips, Biodistribution and imaging studies of Technetium 99m labelled liposomes in rats with focal infection, J. Nucl. Med. 34 (1993) 2160-2168.

[40] G. Gregoriadis, Engineering liposomes for drug delivery: progress and problems, Trends Biotechnol. 13 (1995) 527-537.

[41] A. Sharma, U.S. Sharma, Liposomes in drug delivery: progress and limitations, Int. J. Pharm. 154 (1997) 123-140.

[42] A. Bunker, A. Magarkar, T. Viitala, Rational design of liposomal drug delivery systems, a review: combined experimental and computational studies of lipid membranes, liposomes and their PEGylation, BBA - Biomembranes 2016 (1858) 2334-2352.

[43] H. Daraee, A. Etemadi, M. Kouhi, S. Alimirzalu, A. Akbarzadeh, Application of liposomes in medicine and drug delivery, Artif. Cells Nanomed. Biotechnol. 44 (2016) 381-391.

[44] J.H. Kang, W.Y. Jang, Y.T. Ko, The effect of surface charges on the cellular uptake of liposomes investigated by live cell imaging, Pharm. Res. (2017) 1-14.

[45] K. Greish, Enhanced permeability and retention (EPR) effect of anticancer nanomedicine drug targeting, Methods Mol. Biol. 624 (2010) 25-37.

[46] S.R. Paliwal, R. Paliwal, S.P. Vayas, A review of mechanistic insight and application of pH-sensitive liposomes in drug delivery, Drug Deliv. 22 (2015) 231-242.

[47] V.P. Torchilin, M.I. Papisov, Why do polyethelene glycol-coated liposomes circulated so long?:molecular mechanism of liposome steric protection with polethylene glycol: role of polymer chain flexibility, J. Liposome Res. 4 (2008) 725-739.

[48] B. Goins, A. Bao, W.T. Phillips, Techniques for loading technetium-99m and rhenium-186/188 radionuclides into preformed liposomes for diagnostic imaging and radionuclide therapy, Methods Mol. Biol. 1522 (2017) 155-178.

[49] M.-H. Chen, C.-H. Chang, Y.-J. Chang, L.-C. Chen, C.-Y. Yu, Y.-H. Wu, et al., MicroSPECT/CT imaging and pharmacokinetics of ${ }^{188} \mathrm{Re}$-(DXR)-liposome $\mathrm{n}$ human colorectal adenocarcinoma-bearing mice, Anticancer Res. 30 (2010) 65-72.

[50] C.-C. Tsai, C.-H. Chang, L.-C. Chen, Y.-J. Chang, K.-L. Lan, Y.-H. Wu, et al., Biodistribution and pharmacokinetics of 188Re-liposomes and their comparative therapeutic efficacy with 5 -fluorouracil in a C26 colonic peritoneal carcinomatosis mice, Int. J. Nanomedicine 6 (2011) 2607-2619.

[51] S. Li, B. Goins, L. Zhang, A. Bao, A novel multifunctional theranostic liposome drug delivery system: construction, characterization, and multimodality MR, Near-infrared fluorescent and nuclear imaging, Bioconjug. Chem. 23 (2012) 1322-1332.

[52] A. Soundararajan, A. Bao, W.T. Phillips, L.M. McManus, B.A. Goins, Chemoradionuclide therapy with (186)re-labelled liposomal doxorubicin: toxicity, dosime- 
[54] H. Belhaj-Tayeb, D. Briane, J. Vergote, S. Kothan, G. Léger, S.E. Bendada, et al., In vitro and in vivo study of 99mTc-MIBI encapsulated in PEG-liposomes: a promising radiotracer for tumour imaging, EJNMMI 30 (2003) 502-509.

[55] B. Goins, R. Klipper, A.S. Rudolph, W.T. Phillips, Use of technetium-99m-liposomes in tumour imaging, J. Nucl. Med. 35 (1994) 1491-1498.

[56] E.T. Dams, W.J. Oyen, O.C. Boerman, G. Storm, P. Laverman, P.J. Kok, et al., 99m Tc-PEG liposomes for the scintigraphic detection of infection and inflammation: clinical evaluation, J. Nucl. Med. 41 (2000) 622-630.

[57] D.S. Abou, D.L.J. Thorek, N.N. Ramos, M.W.H. Pinkse, H.T. Wolterbeek, S.D. Carlin, et al., 89Zr-labeled paramagnetic octreotide-liposomes for PET-MR imaging of cancer, Pharm. Res. 30 (2013) 878-888.

[58] S.W. Zeilhuis, J.-H. Seppenwoolde, V.A.P. Mateus, C.J.G. Bakker, G.C. Krijger, G. Storm, et al., Lanthanide-loaded liposomes for multimodality imaging and therapy, Cancer Biother. Radiopharm. 21 (2006) 520-527.

[59] T.H. Chow, Y.Y. Lin, H.-E. Wang, Y.-L. Tseng, V.F. Pang, S.-J. Wang, et al., Diagnostic and therapeutic evaluation of 111In-vinorelbine-liposomes in a human colorectal carcinoma HT-29/luc-bearing animal model, Nucl. Med. Biol. 35 (2008) 623-634.

[60] A. Kaul, S. Chaturvedi, A. Attri, M. Kalra, A.K. Mishra, Targeted theranostic liposomes: rifampicin and ofloxacin loaded pegylated liposomes for theranostic application in mycobacterial infections, RSC Adv. 6 (2016) 28919-28926.

[61] R.M. De Kruijff, A.J.G.M. Van der Meer, C.A.A. Windmeijer, J.M.M. Kouwenberg, A. Morgenstern, F. Bruchertseifer, et al., The therapeutic potential of polymersomes loaded with 225Ac evaluated in 2D and 3D in vitro glioma models, Eur. J. Pharm. Biopharm. 127 (2018) 85-91.

[62] A.L. Petersen, T. Binderup, R.I. Jølck, J. Rasmussen, J.R. Henriksen, A.K. Pfeifer, et al., Positron emission tomography evaluation of somatostatin receptor targeted 64Cu-TATE-liposomes in a human neuroendocrine carcinoma mouse model, J. Control. Release 160 (2012) 254-263.

[63] J. Kim, D.N. Pandya, W. Lee, J.W. Park, Y.J. Kim, W. Kwak, et al., Vivid tumour imaging utilizing liposome-carried bimodal radiotracer, ACS Med. Chem. Lett. 5 (2015) 390-394.

[64] C.-W. Hsu, Y.-J. Chang, C.-H. Chang, L.-C. Chen, K.-L. Lan, G. Ting, et al., Compar ative therapeutic efficacy of rhenium-188 radiolabeled-liposome and 5-fluorouracil in LS-174T human colon carcinoma solid tumour xenografts, Cancer Biother. Radiopharm. 27 (2012) 481-489.

[65] C.-M. Liu, C.-H. Chag, Y.-J. Chang, W.-C. Hsu, L.-C. Chen, H.-L. Chen, et al., Preliminary evaluation of acute toxicity of ${ }^{188}$ Re-BMEDA-liposome in rats, J. Appl. Toxicol. 30 (2010) 680-687.

[66] L. Chi-Mou, T. Chai-Che, Y. Chia-Yu, L. Wan-Chi, H. Chung-Li, C. Tsui-Jung, et al., Extended acute toxicity study of ${ }^{188}$ Re-liposome in rats, J. Appl. Toxicol. 33 (2013) 886-893.

[67] W.-H. Hsu, S.-Y. Liu, Y.-J. Chang, C.-H. Chang, G. Ting, T.-W. Lee, The PEGylated liposomal doxorubicin improves the delivery and therapeutic efficiency of ${ }^{188}$ Re-Liposome by modulating phagocytosis in C26 murine colon carcinoma tumour model, Nucl. Med. Biol. 41 (2014) 765-771.

[68] C.-H. Chang, C.-Y. Liu, C.-W. Chi, H.-L. Yu, T.-J. Chang, T.-H. Tsai, et al., External beam radiotherapy synergizes ${ }^{188} \mathrm{Re}$-liposome against human oesophageal cancer xenograft and modulates ${ }^{188}$ Re-liposome pharmacokinetics, Int. J. Nanomedicine 10 (2015) 3641-3649.

[69] E. Allard, F. Hindre, C. Passirani, L. Lemaire, N. Lepareur, N. Noiret, et al., ${ }^{188}$ Re-loaded lipid nanocapsules as a promising radiopharmaceutical carrier for internal radiotherapy of malignant gliomas, EJNMMI 35 (2008) 1838-1846.

[70] S.-X. Wang, A. Bao, S.J. Herrera, W.T. Phillips, B. Goins, C. Santoyo, et al., Intraoperative ${ }^{186}$ Re-liposome radionuclide therapy in a head and neck squamous cell carcinoma xenograft positive surgical margin model, Clin. Cancer Res. 14 (2008) 3975-3983.

[71] C.L. Zavaleta, B.A. Goins, A. Bao, L.M. McManus, C.A. McMahan, W.T. Phillips, Imaging of ${ }^{186} \mathrm{Re}$-liposome therapy in ovarian cancer xenograft model of peritoneal carcinomatosis, J. Drug Target. 16 (2008) 626-637.

[72] Y.-J. Chang, C.-Y. Yu, C.-W. Hsu, W.-C. Lee, S.-J. Chen, C.-H. Chang, et al., Molecular imaging and therapeutic efficacy of ${ }^{188}$ Re-(DXR)-liposome-BNN in AR42J pancreatic tumour-bearing mice, Oncol. Rep. 28 (2012) 1736-1742.

[73] L.-C. Chen, Y.-H. Wu, I.-H. Liu, C.-L. Ho, W.-C. Lee, C.-H. Chang, et al., Pharmacokinetics, dosimetry and comparative efficacy of ${ }^{188} \mathrm{Re}$-liposome and 5-Fu in a CT26-luc lung-metastatic mice model, Nucl. Med. Biol. 39 (2012) 35-43.

[74] W.T. Phillips, B. Goins, A. Bao, D. Vargas, J.E. Guttierez, A. Trevino, et al., Rhenium-186 liposomes as convection-enhanced nanoparticle brachytherapy for treat ment of glioblastoma, Neuro-oncology 14 (2012) 416-425.

[75] C.-M. Liu, W.-C. Lee, C.-Y. Yu, K.-L. Lan, C.-H. Chang, G. Ting, et al., Comparison of the therapeutic efficacy of ${ }^{188}$ Rhenium-liposomes and liposomal doxurbicin in a 4T1 murine orthotopic breast cancer model, Oncol. Rep. 5 (2012) 678-684.

[76] Y.-A. Shen, K.-L. Lan, C.-H. Chang, L.-T. Lin, C.-L. He, P.-H. Chen, et al., Intraperitoneal (188)Re-liposome delivery switches ovarian cancer metabolism from glycolysis to oxidative phosphorylation and effectively controls ovarian tumour growth in mice, Radiother. Oncol. 119 (2016) 282-290.

[77] J. Cao, Y. Wang, J. Yu, J. Xia, C. Zang, D. Yin, et al., Preparation and radiolabeling of surface-modified magnetic nanoparticles with rhenium-188 for magnetic targeted radiotherapy, J. Magn. Magn. Mater. 277 (2004) 165-174.

[78] S. Liang, Y. Wang, C. Zang, X. Liu, Z. Liu, R. Xu, et al., Synthesis of amino-modified magnetite nanoparticles coated with Hepama- 1 and radiolabeled with ${ }^{188} \mathrm{Re}$ for bio-magnetically targeted radiotherapy, J. Radioanal. Nucl. Ch. 269 (2006) 3-7.

[79] S.-J. Wang, W.-J. Lin, M.-N. Chen, C.-S. Chi, J.-T. Chen, W.-L. Ho, et al., Intratumoral injection of rhenium-188 microspheres into an animal model of hepatoma, J. Nucl. Med. 39 (1998) 1752-1757.

[80] G. Wunderlich, J. Pinkert, M. Stintz, J. Kotzerke, Labelling and biodistribution of different particle materials for radioembolization therapy with ${ }^{188} \mathrm{Re}$, Appl. Radiat
[81] C. Glaus, R. Rossin, M.J. Welch, G. Bao, In vivo evaluation of 64Cu-labeled magnetic nanoparticles as a dual-modality PET/MR imaging agent, Bioconjug. Chem. 21 (2010) 715-722.

[82] T.-H. Chow, Y.-Y. Lin, J.-J. Hwang, H.-E. Wang, Y.-L. Tseng, V.F. Pang, et al., Therapeutic efficacy evaluation of ${ }^{111}$ In labelled PEGylated liposomal vinorelbine in murine colon carcinoma with multimodalities of molecular imaging, J. Nucl. Med. 50 (2009) 2073-2081.

[83] Y.Y. Lin, J.-J. Li, C.-H. Chang, Y.-C. Lu, J.-J. Hwang, Y.-L. Tseng, et al., Evaluation of pharmacokinetics of ${ }^{111}$ In-labeled VNB-PEGylated liposomes after intraperitoneal and intravenous administration in a tumour/ascites mouse model, Cancer Biother. Radiopharm. 24 (2009) 453-460.

[84] Y.-J. Chang, W.-H. Hsu, C.-H. Chang, K.-L. Lan, G. Ting, T.-W. Lee, Combined therapeutic efficacy of ${ }^{188} \mathrm{Re}$-liposomes and sorafeni in an experimental colorectal cancer liver metastasis model by intrasplenic injection of C26-luc murine colon cancer cells, Mol. Clin. Oncol. 2 (2014) 380-384.

[85] D. Olsen, J.T. Jørgensen, Companion diagnostics for targeted cancer drugs - clinical and regulatory aspects, Front. Oncol. 4 (2015) 1-8.

[86] C.A. Presant, G. Ksionski, R. Crossley, ${ }^{111}$ In-labeled liposomes for tumour imaging: clinical results of the international liposome imaging study, J. Liposome Res. 1 (1990) 431-436.

[87] A. Kubo, H. Nakamura, T. Sammiya, M. Katayama, T. Hashimoto, S. Hashimoto, et al., Indium-111-labelled liposomes: dosimetry and tumour detection in patients with cancer, EJNMMI 20 (1993) 107-113.

[88] C.A. Presant, A.F. Turner, R.T. Proffitt, Potential for improvement in clinical decision-making: tumour imaging with in-111 labelled liposomes results of a phase ii-iii study, J. Liposome Res. 4 (1994) 985-1008.

[89] G.M. Jensen, T.H. Bunch, Conventional liposome performance and evaluation: lessons from the development of vescan, J. Liposome Res. 17 (2007) 121-137.

[90] K.J. Harrington, G. Rowlinson-Busza, K.N. Syrigos, P.S. Uster, R.M. Abra, J.S.W. Stewart, Biodistribution and pharmacokinetics of ${ }^{111}$ In-DTPA-labelled pegylated liposomes in a human xenograft model: implications for novel targeting strategies, Br. J. Cancer 83 (2000) 232-238.

[91] A. Polyák, I. Hajdu, M. Bodnár, G. Trencsényi, Z. Pöstényi, V. Haász, et al., (99m)Tc-labelled nanosystem as tumour imaging agent for SPECT and SPECT/CT modalities, Int. J. Pharm. 5 (2013) 10-17.

[92] S. Dagar, A. Krishnadas, I. Rubinstein, M.J. Blend, H. Önyüksel, VIP grafted sterically stabilized liposomes for targeted imaging of breast cancer: in vivo studies, J. Control. Release 91 (2003) 123-133.

[93] M.M. Kleiter, L.A. Mohammadian, N. Niehaus, I. Spasojevic, L. Sanders, B.L. Viglianti, et al., A tracer dose of technetium-99m-labeled liposomes can estimate the effect of hyperthermia on intratumoral doxil extravasation, Clin. Cancer Res. 15 (2006) 6800-6807.

[94] I. Ogihara, S. Kojima, M. Jay, Tumor uptake of ${ }^{67} \mathrm{Ga}$-carrying liposomes, EJNMMI 11 (1986) 405-411.

[95] I. Ogihara-Umeda, S. Kojima, Increased delivery of galium-67 to tumours using serum-stable liposomes, J. Nucl. Med. 29 (1988) 516-523.

[96] I. Ogihara-Umeda, S. Kojima, Cholesterol enhances the delivery of liposome-encapuslated gallium-67 to tumours, EJNMMI 15 (1989) 612-617.

[97] R. Rossin, D. Pan, K. Qi, J.L. Turner, X. Sun, K.L. Wooley, et al., ${ }^{64} \mathrm{Cu}-$ labeled folate-conjugated shell cross-linked nanoparticles for tumour imaging and radiotherapy: synthesis, radiolabeling, and biologic evaluation, J. Nucl. Med. 46 (2005) 1210-1218.

[98] A.W. Wong, E. Ormsby, H. Zhang, J.W. Seo, L.M. Mahakian, C.F. Caskey, et al., A comparison of image contrast with ${ }^{64} \mathrm{Cu}$-labeled long circulating liposomes and ${ }^{18}$ F-FDG in a murine model of mammary carcinoma, Am. J. Nucl. Med. Mol. Imag. 3 (2013) 32-43.

[99] L.M. Mahakian, D.G. Farwell, H. Zhang, J.W. Seo, B. Poirier, S.P. Tinling, et al., Comparison of PET imaging with ${ }^{64} \mathrm{Cu}$-liposomes and ${ }^{18} \mathrm{~F}$-FDG in the 7,12-dimethylbenz[a]anthracene(DMBA)-induced hamster buccal pouch model of oral dysplasia and squamous cell carcinoma, Mol. Imaging Biol. 16 (2014) 284-292.

[100] I. Ogihara-Umeda, T. Sasaki, H. Nishigori, Active removal of radioactivity in the blood circulation using biotin-bearing liposomes and avidin for rapid tumour imaging, EJNMMI 20 (1993) 170-172.

[101] I. Ogihara-Umeda, T. Sasaki, H. Toyama, K. Oda, M. Senda, H. Nishigori, Rapid tumour imaging by active background reduction using biotin-bearing liposomes and avidin, Cancer Res. 54 (1994) 463-467.

[102] E. Jestin, M. Mougin-Degraef, A. Faivre-Chauvet, P. Remaud-Le Saëc, F. Hindre, J.P. Benoit, et al., Radiolabeling and targeting of lipidic nanocapsules for applications in radioimmunotherapy, Q. J. Nucl. Med. 51 (2007) 51-60.

[103] M. Mougin-Degraef, C. Bourdeau, E. Jestin, C. Saï-Maurel, M. Bourgeois, P. Remaud-Le Saëc, et al., Doubly radiolabeled liposomes for pretargeted radioimmunotherapy, Int. J. Pharm. 344 (2007) 110-117.

[104] A. Signore, A.W.J.M. Glaudemans, F. Galli, F. Rouzet, Imaging infection and inflammation, Biomed. Res. Int. 2015 (2015) 1-3.

[105] J.R. Morgan, L.A. Williams, C.B. Howard, Technetium-labelled liposome imaging for deep-seated infection, Br. J. Radiol. 58 (1985) 35-39.

[106] B.D. Williams, M.M. O'Sullivan, G.S. Saggu, K.E. Williams, L.A. Williams, J.R. Morgan, Synovial accumulations of technetium labelled liposomes in rheumatoid arthritis, Ann. Rheum. Dis. 46 (1987) 314-318.

[107] M.M. O'Sullivan, N. Powell, A.P. French, K.E. Williams, J.R. Morgan, B.D. Williams, Inflammatory joint disease: a comparison of liposome scanning, bone scanning and radiography, Ann. Rheum. Dis. 47 (1988) 485-491.

[108] A. Brouwers, D. De Jong, E.T. Dams, W.J. Oyen, O.C. Boerman, P. Laverman, et al., Tc-99m-PEG-liposomes for the evaluation for colitis in Chron's disease, J. Drug Target. 8 (2000) 225-233.

[109] J.R. Morgan, K.E. Williams, L.L. Davies, K. Leach, M. Thomson, L.A.P. Williams, Localisation of experimental staphylococcal abscesses by $99 \mathrm{mTc}$-Technetium-labelled liposomes, J. Med. Microbiol. 14 (1981) 213-217. 
[110] I.A. Bakker-Woudenberg, A.F. Lokerse, M.T. Ten Kate, J.W. Mouton, M.C. Woodle, G. Storm, Liposomes with prolonged blood circulation and selective localization in Klebsiella pneumonia-infected lung tissue, J. Infect. Dis. 168 (1993) 164-171.

[111] V.D. Awasthi, B. Goins, R. Klipper, R. Loredo, D. Korvick, W.T. Phillips, Imaging experimental osteomyelitis using radiolabeled liposomes, J. Nucl. Med. 36 (1998) 1089-1094.

[112] M.J. Becker, E.T. Dams, S. De Marie, W.J. Oyen, O.C. Boerman, M.H. Fens, et al., Scintigraphic imaging using ${ }^{99 \mathrm{~m}}$ Tc-labeled PEG liposomes allows early detection of experimental invasive pulmonary aspergillosis in neturopenic rats, Nucl. Med. Biol. 29 (2002) 177-184.

[113] W.G. Love, N. Amos, I.W. Kellaway, B.D. Williams, Specific accumulation of technetium- $99 \mathrm{~m}$ radiolabelled, negative liposomes in the inflamed paws of rats with adjuvant induced arthritis: effect of liposome size, Ann. Rheum. Dis. 48 (1989) 143-148.

[114] V.A. Carmo, C.S. Ferrari, E.C. Reis, G.A. Ramaldes, M.A. Pereira, M.C. De Oliveira, et al., Biodistribution study and identification of inflammation sites using 99mTc-labelled stealth pH sensitive liposomes, Nucl. Med. Commun. 29 (2008) 33-38.

[115] W.J. Oyen, O.C. Boerman, G. Storm, L. Van Bloois, E.B. Koenders, R.A. Claessens, et al., Detecting infection and inflammation with technetium-99m-labeled stealth liposomes, J. Nucl. Med. 37 (1996) 1392-1397.

[116] W.J. Oyen, O.C. Boerman, G. Storm, L. Van Bloois, E.B. Koenders, D.J. Crommelin, et al., Labelled stealth liposomes in experimental infection: an alternative to leukocyte scintigraphy?, Nucl. Med. Commun. 17 (1996) 742-748.

[117] S.M.Z.M.D. Ferreira, G.P. Domingos, D.S. Ferreira, T.G.R. Rocha, R. Serakides, C.M. De Faria Rezende, et al., Technetium-99m-labeled ceftizoxime loaded long-circulating and pH-sensitive liposomes used to identify osteomyelitis, Bioorg. Med. Chem. Lett. 22 (2012) 4605-4608.

[118] C. Tilcock, M. Yap, M. Szucs, D. Utkhede, PEG-coated lipid vesicles with encapsulated technetium-99m as blood pool agents for nuclear medicine, Nucl. Med. Biol. 21 (1994) 165-170.

[119] B. Goins, W.T. Phillips, R. Klipper, Blood-pool imaging using Tecnetium-99m-labeled liposomes, J. Nucl. Med. 37 (1996) 1374-1379.

[120] N. Oku, M. Yamashita, Y. Katayama, T. Urakami, K. Hatanaka, K. Shimizu, et al., PET imaging of brain cancer with positron emitter-labelled liposomes, Int. J. Pharm. 403 (2011) 170-177.

[121] V. Azarian, A. Gangloff, Y. Seimbille, S. Delaloye, J. Czernin, M.E. Phelps, et al. Synthesis and liposome encapsulation of a novel 18F-conjugate of $\omega$-conotoxin GVIA for the potential imaging of N-type $\mathrm{Ca} 2+$ channels in the brain by positron emission tomography, J. Label. Compd. Rad. 49 (2006) 269-283.

[122] V.N. Tiwari, Y. Kiyono, M. Kobayashi, T. Mori, T. Kudo, H. Okazawa, et al., Automatic labelling method for injectable 15O-oxygen using haemoglobin-containing liposome vesicles and its application for measurement of brain oxygen consumption by PET, Nucl. Med. Biol. 37 (2010) 77-83.

[123] H.P. Stoll, G.D. Hutchins, W.L. Winkle, A.T. Nguyen, C.R. Appledorn, I. Janzen, et al., Advantages of short-lived positron-emitting radioisotopes for intracoronary radiation therapy with liquid-filled balloons to prevent restenosis, J. Nucl. Med. 42 (2001) 1375-1383.

[124] A.L.B. De Barros, L.D. Mota, M.M. Coelho, N.C. Corrêa, A.M. De Góes, M.C Oliveira, et al., Bombesin encapsulated in long-circulating pH-sensitive liposomes as a radiotracer for breast tumour identification, J. Biomater. Nanotech. 11 (2015) 342-350.

[125] N.K. Varde, D.W. Pack, Microspheres for controlled release drug delivery, Expert. Opin. Biol. Ther. 4 (2004) 35-51.

[126] A.L. Lewis, M.V. Gonzalez, A.W. Lloyd, B. Hall, Y. Thang, S.L. Willis, et al., DC bead: in vitro characterization of a drug-delivery device for transarterial chemoembolization, J. Vasc. Interv. Radiol. 17 (2006) 335-342.

[127] Y. Zang, X. Wang, T. Su, D. Chen, W. Zhong, A doxorubicin delivery system: samarium/mesoporous bioactive glass/ alginate composite microspheres, Mater. Sci. Eng. C 67 (2016) 205-213.

[128] I. Wollner, C. Knutsen, P. Smith, D. Prieskorn, C. Chrisp, J. Andrews, et al., Effects of hepatic arterial Yttrium 90 glass microspheres in dogs, Cancer 61 (1988) 1336-1344.

[129] M.J. Herba, F.F. Illescas, M.P. Thirlwell, G.J. Boos, L. Rosenthall, A. Atri, et al., Hepatic malignancies: improved treatment with intraarterial Y-90, Australas. Radiol. 169 (1988) 311-314.

[130] C.Y.O. Wong, R. Salem, S. Raman, V.L. Gates, H.J. Dworkin, Evaluating ${ }^{90}$ Y-glass microsphere treatment response of unresectable colorectal liver metastases by [18 F]FDG PET: a comparison with CT or MRI, EJNMMI 29 (2002) 815-820.

[131] J.E. Goin, R. Salem, B.I. Carr, J.E. Dancey, M.C. Soulen, J.F. Geschwind, et al., Treatment of unresectable hepatocellular carcinoma with intrahepatic yttrium 90 microspheres: factors associated with liver toxicities, J. Vasc. Interv. Radiol. 16 (2005) 205-213.

[132] P. Hilgard, M. Hamami, A.E. Fouly, A. Scherag, S. Müller, J. Ertle, et al., Radioembolization with yttrium-90 glass microspheres in hepatocellular carcinoma: European experience on safety and long-term survival, Hepatology 52 (2010) 1741-1749.

[133] M. Shaheen, M. Hassanian, M. Aljiffry, T. Cabrera, P. Chaudhury, E. Simoneau, et al., Predicators of response to radio-embolization (TheraSphere $\left.{ }^{\circledR}\right)$ treatment of neuroendocrine liver metastasis, HPB 14 (2012) 60-66.

[134] A. Riza, R. Awais, R. Salem, Side effects of Yttrium-90 radioembolization, Font. Oncol. 4 (2014) 1-29.

[135] C. Mosconi, A. Cappelli, C. Pettinato, R. Golfieri, Radioembolization with Yttrium-90 microspheres in hepatocellular carcinoma: role and perspectives, World J. Hepatol. 7 (2015) 738-752.

[136] B.N. Gray, J.E. Anderson, M.A. Burton, G. Van Hazel, J. Codde, C. Morgan, et al., Regression of liver metastases following treatment with yttrium-90 microspheres, Aust. NZ J. Surg. 62 (1992) 105-110. versus fluorouracil/leucovorin chemotherapy alone in advanced colorectal cancer, J. Surg. Oncol. 88 (2004) 78-85.

[138] A.S. Kennedy, W.A. Dezarn, P. McNellie, D. Coldwell, C. Nutting, D. Carter, et al. Radioembolization for unresectable neuroendocrine hepatic metastases using resin 90Y-microspheres: early results in 148 patients, Am. J. Clin. Oncol. 31 (2008) 271-279.

[139] R. Cianni, C. Urigo, E. Notarianni, A. Saltarelli, R. Salvatori, V. Pasqualini, et al., Selective internal radiation therapy with SIR spheres for the treatment of unresectable colorectal hepatic metastases, Cardiovasc. Interv. Radiol. 32 (2009) $1179-1186$.

[140] G. Schmid, Nanoparticles: From Theory to Application, 2nd ed, John Wiley \& sons, 2011.

[141] J. Singh, T. Garg, G. Rath, A.K. Goyal, Advances in nanotechnology-based carrier systems for targeted delivery of bioactive drug molecules with special emphasis on immunotherapy in drug resistant tuberculosis-a critical review, Drug Deliv. 23 (2015) 1676-1698.

[142] E.C. Pratt, T.M. Shaffer, J. Grimm, Nanoparticles and radiotracers: advances toward radionanomedicine, Wiley Interdiscip. Rev. Nanomed. Nanobiotechnol. 8 (2016) 872-890.

[143] B.I. Kharisov, O.V. Kharissova, S.S. Berdonosov, Radioactive nanoparticles and their main applications: recent advances, Rec. Pat. Nanotechnol. 8 (2014) 79-96.

[144] S.-M. Kim, M.K. Chae, M.S. Yim, I.H. Jeong, J. Cho, C. Lee, et al., Hybrid PET/MR imaging of tumours using an oleanolic acid-conjugated nanoparticle, Biomaterials 34 (2013) 8114-8121.

[145] B.R. Jarrett, B. Gustafsson, D.L. Kukis, A.Y. Louie, Synthesis of 64Cu-labeled mag netic nanoparticles for multimodal imaging, Bioconjug. Chem. 19 (2008) $1496-1504$

[146] M. Nahrendorf, H. Zhang, S. Hembrador, P. Panizzi, D.E. Sosnovik, E. Aikawa, et al., Nanoparticle PET-CT imaging of macrophages in inflammatory atherosclerosis, Circulation 177 (2008) 379-387.

[147] E. Boros, A.M. Bowen, L. Josephson, N. Vasdev, J.P. Holland, Chelate-free metal ion binding and heat-induced radiolabeling of iron oxide nanoparticles, Chem. Sci. 6 (2015) 225-236.

[148] J.-S. Choi, J.C. Park, H. Nah, S. Woo, J. Oh, K.M. Kim, et al., A hybrid nanoparticle probe for dual-modality positron emission tomography and magnetic resonance imaging, Angew. Chem. 47 (2008).

[149] H.-Y. Lee, Z. Li, K. Chen, A.R. Hsu, C. Xu, J. Xie, et al., PET/MRI Dual-modality tumour imaging using arginine-glycine-aspartic (RGD)-conjugated radiolabeled iron oxide nanoparticles, J. Nucl. Med. 49 (2008) 1371-1379.

[150] R. Msri, D. Meier, A.C. Yung, P. Kozlowski, U.O. Häfeli, Development and evaluation of a dual-modality (MRI/SPECT) molecular imaging probe, Nanomedicine 8 (2012) 1007-1016

[151] R.T. De Rosales, R. Tavaré, A. Glaria, G. Varma, A. Protti, P.J. Blower, ${ }^{99 \mathrm{~m}}$ Tc-Bisphosphonate-Iron oxide nanoparticle conjugates for dual-modality biomedical imaging, Bioconjug. Chem. 22 (2011) 455-465.

[152] L. Sandiford, A. Phinikaridou, A. Protti, L.K. Meszaros, X. Cui, Y. Yan, et al., Bisphosphonate-anchored PEGylation and radiolabeling of superparamagnetic iron oxide: long-circulating nanoparticles for in vivo multimodal (T1 MRI-SPECT) imaging, ACS Nano 7 (2013) 500-512.

[153] M. Lijowski, S. Caruthers, G. Hu, H. Zhang, M.J. Scott, T. Williams, et al., High-resolution SPECT-CT/MR molecular imaging of angiogenesis in the Vx3 model, Investig. Radiol. 44 (2009) 15-22.

[154] C.M. Lee, H.J. Jeong, E.M. Kim, D.W. Kim, S.T. Lim, H.T. Kim, et al., Superparamagnetic iron oxide nanoparticles as a dual imaging probe for targeting hepatocytes in vivo, Magn. Reson. Med. 62 (2009) 1440-1466.

[155] T. Buckle, P.T.K. Chin, F.W.B. Van Leeuwen, (Non-targeted) radioactive/fluorescent nanoparticles and their potential in combined pre- and intraoperative imaging during sentinel lymph node resection, Nanotechnology 21 (2010) 1-9.

[156] T. Buckle, A.C. Van Leeuwen, P.T.K. Chin, G. Janssen, S.R. Muller, J. Jonkers, et al., A self-assembled multimodal complex for combine pre-and intraoperative imaging of the sentinel lymph node, Nanotechnology 21 (2010) 1-9.

[157] R. Bekiş, Ǐ. Medine, K. Dağdeviren, T. Ertay, P. Ûnak, A new agent for sentinel lymph node detection: preliminary results, J. Radioanal. Nucl. Chem. 290 (2011) 277-282.

[158] H. Kobayashi, Y. Koyama, T. Barrett, Y. Hama, C.A. Regino, I.S. Shin, et al., Multimodal nanoprobes for radionuclide and five-color near-infrared optical lymphatic imaging, ACS Nano 4 (2007) 258-264.

[159] J.S. Kim, Y.H. Kim, J.H. Kim, K.W. Kang, E.L. Tae, H. Youn, et al., Development and in vivo imaging of a PET/MRI nanoprobe with enhanced NIR fluorescence by dye encapsulation, Nanomedicine 7 (2012) 219-229.

[160] M.S. Bradbury, E. Phillips, P.H. Montero, S.M. Cheal, H. Stambuk, J.C. Durack, et al., Clinically-translated silica nanoparticles as dual-modality cancer-targeted probes for image-guide surgery and interventions, Integr. Biol. 5 (2013) 74-86.

[161] E. Phillips, O. Penate-Medina, P.B. Zanzonico, R.D. Carvajal, P. Mohan, Y. Ye, et al., Clinical translation of an ultrasmall inorganic optical-PET imaging nanoparticle probe, Sci. Transl. Med. 6 (2014) 1-23.

[162] M. Benezra, O. Penate-Medina, P.B. Zanzonico, D. Schaer, H. Ow, A. Burns, et al., Multimodal silica nanoparticles are effective cancer-targeted probes in a model of human melanoma, J. Clin. Invest. 121 (2011) 2768-2780.

[163] Chung DS, Kang K, Jeon Y, Kim Y, Alothman ZA, Ahmed AYH, et al. Fluorescen silica nanoparticle with radioactive tag and the detecting method of pet and fluorescent dual imaging using thereof. Google Patents; 2009.

[164] K. Chen, Z.B. Li, H.C. Wang, W., Chen X., Dual-modality optical and positron emission tomography imaging of vascular endothelial growth factor receptor on tumour vasculature using quantum dots, EJNMMI 35 (2008) 2235-2244.

[165] W. Cai, K. Chen, Z.B. Li, S.S. Gambhir, X. Chen, Dual-function probe for PET and near-infrared fluorescence imaging of tumour vasculature, J. Nucl. Med. 48 (2007) 1862-1870. 
[166] Y. Yang, Y. Sun, T. Cao, J. Peng, Y. Liu, Y. Wu, et al., Hydrothermal synthesis of NaLuF4:153Sm, Yb, Tm nanoparticles and their application in dual-modality upconversion luminescence and SPECT bioimaging, Biomaterials 34 (2013) 774-783.

[167] M. Miyata, H. Tomita, K. Watanabe, J. Kawarabayashi, T. Iguchi, Development of TOF-PET using Cherenkov radiation, J. Nucl. Sci. Technol. 43 (2006) 339-343.

[168] A. Ruggiero, J.P. Holland, A.L. Lewis, J. Grimm, Cerenkov luminescence imaging of medical isotopes, J. Nucl. Med. 51 (2010) 1123-1130.

[169] D.J. Thorek, R. Roberson, W.A. Bacchus, J. Hahn, J. Rothberg, B.J. Beattie, J. Grimm, Cerenkov imaging-a new modality for molecular imaging, Am. J. Nucl. Med. Mol. Imaging 2 (2012) 163-173.

[170] R.S. Dothager, R.J. Goiffon, E. Jackson, S. Harpstrite, D. Piwnica-Worms, Cerenkov radiation energy transfer (CRET) imaging: a novel method for optical imaging of PET isotopes in biological systems, PLoS One 5 (2010) 1-7.

[171] C. Sun, G. Pratx, C.M. Carpenter, H. Liu, Z. Cheng, S.S. Gamhir, et al., Synthesis and radioluminescence of PEGylated Eu3 +-doped nanophosphors as bioimaging probes, Mater. Views 23 (2011) H195-H199.

[172] X. Ma, F. Kang, F. Xu, A. Feng, Y. Zhao, T. Lu, et al., Enhancement of cerenkov luminescence imaging by dual excitation of Er3 +, Yb3 + - doped rare-earth microparticles, Pols One 8 (2013) 1-8.

[173] Z. Hu, Y. Qu, K. Wang, X. Zhang, J. Zha, T. Song, et al., In vivo nanoparticle-mediated radiopharmaceutical-excited fluorescence molecular imaging, Nat. Commun. 6 (2015) 1-12.

[174] Y. Wang, Y. Liu, H. Luehmann, X. Xia, D. Wan, C. Cutler, et al., Radioluminescent gold nanocages with controlled radioactivity for real-time in vivo imaging, Nano Lett. 13 (2013) 581-585.

[175] H. Liu, X. Zhang, B. Xing, P. Han, S.S. Gambhir, Z. Cheng, Radiation-luminescence excited quantum dots for in vivo multiplexed optical imaging, Small 6 (2010) 1087-1091.

[176] N.K. Devaraj, E.J. Keliher, G.M. Thurber, M. Nahrendorf, R. Weisleder, ${ }^{18} \mathrm{~F}$ labelled nanoparticles for in vivo PET-CT imaging, Bioconjug. Chem. 20 (2009) 397-401.

[177] J. Xie, K. Chen, J. Huang, S. Lee, J. Wang, J. Gao, et al., PET/NIRF/MRI triple functional iron oxide nanoparticles, Biomaterials 31 (2010) 3016-3022.

[178] M. Yang, K. Cheng, S. Qi, H. Liu, Y. Jiang, H. Jiang, et al., Affibody modified and radiolabeled gold-iron oxide heteronanostructures for tumour PET, optical and MR imaging, Biomaterials 34 (2013) 2796-2806.

[179] J. Shi, T.W.B. Liu, J. Chen, D. Green, D. Jaffray, B.C. Wilson, et al., Transforming a targeted porphyrin theranostic agent into a PET imaging probe for cancer, Theranostics 1 (2011) 363-370.

[180] T.W. Liu, T.D. MacDonald, C.S. Jin, J.M. Gold, R.G. Bristow, B.C. Wilson, et al., In herently multimodal nanoparticle-driven tracking and real-time delineation of orthotopic prostate tumours and micrometastases, ACS Nano 7 (2013) 4221-4232.

[181] J. Zhou, M. Yu, Y. Sun, X. Zhang, X. Zhu, Z. Wu, et al., Flourine-18-labeled $\mathrm{Gd}^{3+} / \mathrm{Yb}^{3+} / \mathrm{Er}^{3+}$ co-doped NaYF4 nanophosphors for multimodality PET/MR/ UCL imaging, Biomaterials 32 (2011).

[182] J. Lee, T.S. Lee, J. Ryu, S. Hong, M. Kang, K. Im, et al., RGD peptide- conjugated multimodal NaGdF4"yb3 + /Er3 + nanophosphors for upconversion luminescence, MR and PET imaging of tumour angiogenesis, J. Nucl. Med. 54 (2013) 96-103.

[183] H.-W. Kao, Y.-Y. Lin, C.-C. Chen, K.-H. Chi, D.-C. Tien, C.-C. Hsia, et al., Evaluation of EGFR-targeted radioimmuno-gold-nanoparticles as a theranostic agent in a tumour animal model, Bioorg. Med. Chem. Lett. 23 (2013) 3180-3185.

[184] X. Sun, X. Huang, X. Yan, Y. Wang, J. Guo, O. Jacobson, et al., Chelator-free 64Cu-integrated gold nanomaterials for positron emission tomography imaging guided photothermal cancer therapy, ACS Nano 8 (2014) 8438-8446.

[185] Y. Zhao, D. Sultan, L. Detering, S. Cho, G. Sun, R. Pierce, et al., Copper-64-alloyed gold nanoparticles for cancer imaging: improved radiolabel stability and diagnostic accuracy, Angew. Chem. 53 (2014) 156-159.

[186] S.H. Kim, D.Y. Lee, Photothermal therapy with gold nanoparticles as an anticance medication, J. Pharm. Invest. 47 (2017) 19-26.

[187] X. Soa, H. Zang, J.R. Rajian, D.L. Chamberland, P.S. Sherman, C.A. Quesada, et al., 125I-labeled gold nanorods for targeted imaging of inflammation, ACS Nano 5 (2011) 8967-8973.

[188] R. Kannan, A. Zambre, N. Chanda, R. Kulkarni, R. Shukla, K. Katti, et al., Functionalized radioactive gold nanoparticles in tumour therapy, Wiley Interdiscip. Rev. Nanomed. Nanobiotechnol. 4 (2012) 42-51.

[189] A.M. Gamal-Eldeen, D. Moustafa, S.M. El-Daly, E.A. El-Hussieny, S. Saleh, M. Khoobchandani, et al., Photothermal therapy mediated by gum arabic-conjugated gold nanoparticles supresses liver preneoplastic lesions in mice, J. Photochem. Photobiol. B Biol. 163 (2016) 47-56.

[190] A.Y. Al-Yasiri, M. Khoobchandani, C.S. Cutler, L. Watkinson, T. Carmack, C.J. Smith, et al., Mangiferin functionalized radioactive gold nanoparticles (MGF-198AuNPs) in prostate tumour therapy: green nanotechnology for production, in vivo tumour retention and evaluation of therapeutic efficacy, Dalton Trans. (2017) https://doi.org/10.1039/c7dt00383h, In press.

[191] S.J. DeNardo, G.L. DeNardo, A. Natarajan, L.A. Miers, A.R. Foreman, C. Gruettner, et al., Thermal dosimetry predictive of efficacy of ${ }^{111}$ In-ChL6 nanoparticle AMF-induced thermoablative therapy for human breast cancer in mice, J. Nucl. Med. 48 (2007) 437-444.

[192] M. Zhou, R. Zhang, M. Huang, W. Lu, S. Song, M.P. Melancon, et al., A chelator-free multifunctional [64Cu]CuS nanoparticle platform for simultaneous micro-PET/CT imaging and photothermal ablation therapy, J. Am. Chem. Soc. 132 (2010) 1535-15358.

[193] L. Jing, J. Shi, D. Fan, Y. Li, R. Liu, Z. Dai, et al., ${ }^{177} \mathrm{Lu}$-labeled cerasomes encapsulating indocyanine green for cancer theranostics, ACS Appl. Mater. Interfaces 7 (2015) 22095-22105.

[194] H. Wu, M.H. Engelhard, J. Wang, D.R. Fisher, Y. Lin, Synthesis of lutetium phosphate-apoferritin core-shell nanoparticles for potential applications in radioimmunoimaging and radioimmunotherapy of cancers, J. Mater. Chem. 18 (2008) 1779-1783.
[195] J. Chen, H. Wu, D. Han, C. Xie, Using anti-VEGF McAb and magnetic nanoparticles as double-targeting vector for the radioimmunotherapy of liver cancer, Cancer Lett. 231 (2006) 169-175.

[196] S. Iijima, Helical microtubules of graphitic carbon, Nature 354 (1991) 56-58.

[197] A. Bianco, K. Kostarelos, M. Prato, Applications of carbon nanotubes in drug delivery, Curr. Opin. Chem. Biol. 9 (2005) 674-679.

[198] L. Lacerda, A. Bianco, M. Prato, K. Kostarelos, Carbon nanotubes as nanomedicines: from toxicology to pharmacology, Adv. Drug Deliv. Rev. 58 (2006) 1460-1470.

[199] A. Ruggiero, C.H. Villa, J.P. Holland, S.R. Sprinkle, C. May, J.S. Lewis, et al., Imaging and treating tumour vasculature with targeted radiolabeled carbon nanotubes, Int. J. Nanomedicine 5 (2010) 783-802.

[200] Z. Liu, W. Cai, L. He, N. Nakayama, K. Chen, X. Sun, et al., In vivo biodistribution and highly efficient tumour targeting of carbon nanotubes in mice, Nat. Nanotechnol. 2 (2006) 47-52.

[201] R. Singh, D. Pantarotto, L. Lacerda, G. Pastorin, C. Klumpp, M. Prato, et al., Tissue biodistribution and blood clearance rates of intravenously administered carbon nanotube radiotracers, PNAS 103 (2006) 3357-3362.

[202] E.J. Keliher, J. Yoo, M. Nahrendorf, J.S. Lewis, B. Marinelli, A. Newton, et al. ${ }^{89} \mathrm{Zr}$-Labeled Dextran Nanoparticles Allow in Vivo Macrophage Imaging, Bioconjug. Chem. 22 (2011) 2383-2389.

[203] M. Nahrendorf, E. Keliher, B. Marinelli, F. Leuschner, C.S. Robins, R.E. Gerszten, et al., Detection of macrophages in aortic aneurysms by nanoparticle PET-CT, Ar terioscler. Thromb. Vasc. Biol. 31 (2011) 750-757.

[204] C. Zhu, A. Bandekar, S. Ray, M. Pomper, F. Bruchertseifer, A. Morgenstern, et al., Anti-PSMA labelled liposomes loaded with Actinium-225 for potential antivascular alpha-radiotherapy, J. Nucl. Med. 55 (2014) 640.

[205] J. Woodward, S.J. Kennel, A. Stuckey, D. Osborne, J. Wall, A.J. Rondinone, et al. LaPO4 nanoparticles doped with actinium-225 that partially sequester daughter radionuclides, Bioconjug. Chem. 22 (2011) 766-776.

[206] J.V. Rojas, J.D. Woodward, N. Chen, A.J. Rondinone, C.H. Castano, S. Mirzadeh, Synthesis and characterization of lanthanum phosphate nanoparticles as carriers for (223)Ra and (225)Ra for targeted alpha therapy, Nucl. Med. Biol. 42 (2015) 614-620.

[207] J.V. Rojas, J.D. Woodward, N. Chen, A.J. Rondinone, C.H. Castano, S. Mirzadeh, Synthesis and characterization of lanthanum phosphate nanoparticles as carriers for ${ }^{223} \mathrm{Ra}$ and ${ }^{225} \mathrm{Ra}$ for targeted alpha therapy, Nucl. Med. Biol. (2015), In press.

[208] O. Mokhodoeva, M. Vlk, E. Málková, E. Kukleva, P. Mičolová, K. Štamberg, et al. Study of ${ }^{223} \mathrm{Ra}$ uptake mechanism by $\mathrm{Fe}_{3} \mathrm{O}_{4}$ nanoparticles: towards new prospective theranostic SPIONs, J. Nanopart. Res. 18 (2016) 1-12.

[209] A.N. Vasiliev, A. Severin, E. Lapshina, E. Chernykh, S. Ermolaev, et al., Hydroxyapatite particles as carriers for 223Ra, J. Radioanal. Nucl. Chem. 331 (2017) 1503-1509.

[210] A. Piotrowska, S. Męcsyńska-Wielgosz, A. Majkowska-Pilip, P. Koźmiński, G. Wójciuk, E. Cędrowska, et al., Nanozeolite bioconjugates labelled with ${ }^{22}{ }^{3}$ Ra for targeted alpha therapy, Nucl. Med. Biol. 47 (2017) 10-18.

[211] F. Doncongé, T. Pons, C. Pestourie, L. Hérin, B. Thézé, K. Gombert, et al., Fluorine-18-labeled phospholipid quantum dot micelles for in vivo multimodal imaging from whole body to cellular scales, Bioconjug. Chem. 19 (2008) 1921-1926.

[212] R. Zhang, H. Xiong, M. Huang, M. Zhou, Q. Huang, X. Wen, et al., Peptide-conjugated polymeric micellar nanoparticles for Dual SPECT and optical imaging of EphB4 receptors in prostate cancer xenografts, Biomaterials 32 (2011) 5872-5879.

[213] C.R. Moldanodo, N. Gómez-Blanco, M. Jauregui-Osoro, V.G. Brunton, L. Yate, J.C. Mareque-Rivas, QD-filled micelles which combine SPECT and optical imaging with light-induced activation of a platinum(IV) prodrug for anticancer applications, Chem. Commun. 49 (2013) 3985-3987.

[214] Grobler AF, Zeevaart JR. Pharmaceutical composition. Google Patents; 2015. WO 2015063746 A1.

[215] T.M. Allen, P.R. Cullis, Drug delivery systems: entering the mainstream, Science 303 (2004) 1818.

[216] J. Zang, F.X. Gu, J.M. Chan, A.Z. Wang, R.S. Langer, O.C. Farokhzad, Nanoparticles in medicine: therapeutic applications and developments, Clin. Pharm. Therap. 83 (2008) 761-769.

[217] R.R. Sawant, V.P. Torchillin, Challenges in development of targeted liposomal therapeutics, AAPS 14 (2012) 303-315.

[218] L. Sercombe, T. Veerati, F. Moheimani, S.Y. Wu, A.K. Sood, S. Hua, Advances and challenges of liposome assisted drug delivery, Front. Pharmacol. 6 (2015) 286

[219] D.C. Litzinger, A.M.J. Buiting, N. Van Rooijen, L. Huang, Effect of liposome size on the circulation time and intraorgan distribution of amphipathic poly(ethylene glycol)-containing liposomes, Biochim. Biophys. Acta 1190 (1994) 99-107.

[220] V. Torchilin, Tumor delivery of macromolecular drugs based on the EPR effect, Adv. Drug Deliv. Rev. 63 (2011) 131-135.

[221] P. Couvreur, Nanoparticles in drug delivery: past, present and future, Adv. Drug Deliv. Rev. 65 (2013) 21-23.

[222] Theek, B., Baues, M., Ojha, T., Möckel, D., Veettil, S.K., Steitz, J. et al. Sonoporation enhances liposome accumulation and penetration in tumors with low EPR. J. Control. Release, 231:77-85

[223] K. Petrak, Essential properties of drug-targeting delivery systems, Drug Discov. Today 10 (2006) 1667-1673.

[224] T.M. Allen, P.R. Cullis, Liposomal drug delivery systems: from concept to clinical application, Adv. Drug Deliv. Rev. 65 (2013) 36-48.

[225] H. Meada, H. Nakamura, J. Fang, The EPR effect for macromolecular drug delivery to solid tumors: improvement of tumor uptake, lowering of systemic toxicity and distinct tumor imaging in vivo, Adv. Drug Deliv. Rev. 65 (2013) 71-79.

[226] B. Uriely, S. Jeffers, R. Isacson, K. Kutch, D. Wei-Tsao, Z. Yehoshua, E. Libson, F.M. Muggia, D.D. Lasic, Liposomal doxorubicin: antitumor activity and unique toxicities during two complementarty phase I studies, J. Clin. Oncol. 13 (1995) 1777-1785 
[228] W.M. Pardridge, The blood-brain barrier: bottleneck in brain drug development, NeuroRx 2 (2005) 3-14

[229] P. Ehrlich, The partial function of cells, Int. Arch. Allergy Appl. Immunol. 5 (1954) $67-86$.

[230] S. Barua, S. Mitagotri, Challenges associated with penetration of nanoparticles across cell and tissue barriers: a review of current status and future prospects, NanoToday 9 (2014) 223-243.

[231] C. Zylberberg, S. Matosevic, Pharmaceutical liposomal drug delivery: a review of new delivery systems and a look at the regulatory landscape, Drug Deliv. 23 (2016) 3319-3329.
[232] L. Pang, C. Zhang, J. Qin, L. Han, R. Li, C. Hong, H. He, J. Wang, A novel strategy to achieve effective drug delivery: exploit cells as carrier combined with nanoparticles, Drug Deliv. 24 (2017) 83-91.

[233] Bushan B. Introduction to nanotechnology. In: Bushan B (eds). Springer Handbook of Nanotechnology. Springer, Berlin. 2017. Pg. 1-19.

[234] J. Vincent, V.F.C. Szoka, Cancer nanomedicines: so many papers and so few drugs!, Adv. Drug Deliv. Rev. 65 (2013) 80-88. 